\title{
Article \\ Quantitative Airborne Inventories in Dense Tropical Forest Using Imaging Spectroscopy
}

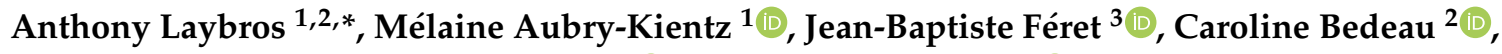 \\ Olivier Brunaux ${ }^{2}$, Géraldine Derroire ${ }^{4}$ (i) and Grégoire Vincent ${ }^{1}$ (D) \\ 1 AMAP, IRD, CNRS, INRA, Université Montpellier, CIRAD, 34000 Montpellier, France; \\ melaine.aubry-kientz@cirad.fr (M.A.-K.); gregoire.vincent@ird.fr (G.V.) \\ 2 Pôle RDI, ONF Guyane, 97300 Cayenne, French Guiana, France; caroline.bedeau@onf.fr (C.B.); \\ olivier.brunaux@onf.fr (O.B.) \\ 3 TETIS, INRAE, University of Montpellier, 500 rue François Breton, 34093 Montpellier CEDEX 5, France; \\ jean-baptiste.feret@teledetection.fr \\ 4 Cirad, UMR EcoFoG (AgroParistech, CNRS, INRAE, Université des Antilles, Université de la Guyane), \\ 97379 Kourou, French Guiana, France; geraldine.derroire@cirad.fr \\ * Correspondence: anthony.laybros@onf.fr
}

Received: 22 April 2020; Accepted: 12 May 2020; Published: 15 May 2020

\begin{abstract}
Tropical forests have exceptional floristic diversity, but their characterization remains incomplete, in part due to the resource intensity of in-situ assessments. Remote sensing technologies can provide valuable, cost-effective, large-scale insights. This study investigates the combined use of airborne LiDAR and imaging spectroscopy to map tree species at landscape scale in French Guiana. Binary classifiers were developed for each of 20 species using linear discriminant analysis (LDA), regularized discriminant analysis (RDA) and logistic regression (LR). Complementing visible and near infrared (VNIR) spectral bands with short wave infrared (SWIR) bands improved the mean average classification accuracy of the target species from $56.1 \%$ to $79.6 \%$. Increasing the number of non-focal species decreased the success rate of target species identification. Classification performance was not significantly affected by impurity rates (confusion between assigned classes) in the non-focal class (up to $5 \%$ of bias), provided that an adequate criterion was used for adjusting threshold probability assignment. A limited number of crowns (30 crowns) in each species class was sufficient to retrieve correct labels effectively. Overall canopy area of target species was strongly correlated to their basal area over 118 ha at 1.5 ha resolution, indicating that operational application of the method is a realistic prospect $\left(R^{2}=0.75\right.$ for six major commercial tree species).
\end{abstract}

Keywords: tropical forest; species diversity; hyperspectral; LiDAR

\section{Introduction}

Tropical forests are a major terrestrial plant biodiversity reservoir [1]. The preservation of this biome is therefore globally important. Persistent deforestation [2] is resulting in drastic declines in biodiversity. From 2000 to 2010, logging in natural forests removed approximately 5\% of the world's forest area [3]. While the biggest drivers for biodiversity change [4] have been shown to be land use change and climate change, logging impact on the biodiversity of various taxonomic groups (mammals, birds, amphibians) is also well documented [5]. Logging impact is not restricted to the removal of a few commercial stems per ha, but also includes damage associated with opening tracks to access to the logging area. Untargeted trees can be wounded in the process of timber felling and hauling, contributing to carbon release [6] and possibly slowing forest recovery rate [7] by favouring fast-growing species such as lianas $[8,9]$. Logging may therefore profoundly modify the floristic 
composition of the exploited plot [10] while disturbing wildlife [11,12]. Proper management of tropical forests is therefore crucial to mitigate the erosion of biodiversity [13].

Remote sensing technologies can provide valuable information for the preservation of tropical forests. Large-scale species distribution maps may provide valuable insights into species autecology and species population dynamics. Imaging spectroscopy has proven useful in monitoring the development of invasive species [14-16]. From a forest management perspective, evaluating abundance and spatial distribution of commercial species will help prioritize areas to be set aside for regeneration purposes and biodiversity conservation, or simply because there is not enough commercially valuable resource for logging operations. Accurate mapping of species prior to opening roads and tracks can therefore support the development of reduced impact logging techniques by minimizing the detrimental impact on soil and forest cover and contributing to protect and maintain forest diversity [17]. This technology is particularly well adapted to tropical forestry, since trees of commercial interest are typically large, upper canopy trees (dominant or emergent) but making up a small part of the entire tree community.

The efficacy of tree species discrimination in tropical forests via airborne imaging spectroscopy has been demonstrated [18-22]. At leaf scale, part of the SWIR1 domain (1467 $\mathrm{nm}$ to $1771 \mathrm{~nm})$ was found to support accurate species identification. The SWIR2 domain (1994 nm to $2435 \mathrm{~nm}$ ) was also found to be important in discriminating species at crown level [23]. A study conducted in semi-deciduous tropical forest [24] reported that including SWIR information (1045 nm to $2395 \mathrm{~nm}$ ) improved their classification accuracy from $64.2 \%$ to $79.8 \%$. While extending the spectral range increases the discriminative power of hyperspectral imagery, it has known drawbacks. Sensors limited to the VNIR domain are lower cost, more widespread, more easily miniaturized to mount on UAV platforms and have better intrinsic performance (higher signal-to-noise ratio). Hence, the balance between costs and benefits of increasing the spectral range should be assessed with respect to the specific task considered.

Improved accuracy has been reported from performing classification at the crown level as opposed to the pixel level $[22,25,26]$. However, segmentation of individual tree crowns (ITCs) in dense canopies remains a difficult task. Light detection and ranging (LiDAR) can help considerably. A recent benchmark study comparing crown segmentation methods using the LiDAR point cloud of a dense tropical canopy [27] identified AMS-3D (Adaptive Mean Shift in 3 Dimensions) as the most effective method. LiDAR and hyperspectral data fusion may further improve our ability to distinguish individual crowns [28].

Most studies in tropical forest so far have focused on discriminating a limited number of species against one another. In the present study, we are interested in retrieving a few target species amongst a very large number of non-focal species. To this end, one might consider focussing the annotation effort on the well-known more easily recognized focal species. This raises the question of the definition of the non-focal species class. A random sample of pixels of the area may capture the diversity of species in the background but will most likely include pixels of the focal species as well. Standard measures of accuracy such as F-measure then become inappropriate during the training stage due to this possible source of bias. A new unbiased criterion was proposed to replace the F-measure in such settings [29] It is based on the evaluation of the focal class (given by the recall metrics) divided by the probability that a sample is classified in the focal class among the non-focal class. This methodology was applied to identify five species on Barro Colorado Island (BCI) [19]. In the latter study, the authors did not specifically study the sensitivity of the classifier to the level of bias (impurity of the non-focal class).

Finally, we go beyond individual tree classification accuracy evaluation by exploring how well one can predict the cumulative basal area of commercial species per unit area from imaging spectroscopy to truly tackle the issue of quantitative forest resource mapping.

Our study starts by examining the benefits of using a SWIR sensor (1000 nm to $2500 \mathrm{~nm}$ ) in conjunction with a VNIR sensor ( $400 \mathrm{~nm}$ to $1000 \mathrm{~nm}$ ) for tree species discrimination. We then move on to the core of our study, which is to evaluate the potential of hyperspectral imagery in an operational setting. We first explore for 20 locally abundant species how much the retrieval rate may depend on the diversity of the set of species among which the target species are mixed. We compare the 
performance of different binary classifiers developed to retrieve target species from wide views of the forest canopy after delineating individual tree crowns using LiDAR data. We further examine the impact of mislabeling of the focal and non-focal classes on the different classifiers' performance. We also briefly examine the impact of the size of the training set representing the species of interest. We finally compare hyperspectral predictions of basal area per species to a large ground inventory database.

\section{Materials and Methods}

\subsection{Study Site}

The study site of Paracou $\left(5^{\circ} 18^{\prime} \mathrm{N}, 52^{\circ} 53^{\prime} \mathrm{W}\right)$ was established during the $1980 \mathrm{~s}$ in French Guiana. The main objective of the experimental set-up was to document the impacts of different silvicultural practices on the dynamics of a tropical rainforest in order to provide guidelines for its sustainable exploitation [30]. Seventy-six $125 \times 125 \mathrm{~m}$ plots (118.75 ha) are regularly monitored (stem girth and vital status being recorded). All trees with a diameter at breast height (DBH) higher than $10 \mathrm{~cm}$ have been identified to species level (or higher order taxon level if species was unknown). At the onset of the experiment, all the trees were geo-located using a meter tape after materializing a $12.5 \times 12.5 \mathrm{~m}$ grid on the ground using strings. Tree location accuracy was estimated to be $+/-2 \mathrm{~m}$.

\subsection{General Methodology Outline}

The general methodology is outlined in Figure 1. LiDAR data was used to segment crowns (Section 2.4.1) over the entire area of interest (118.75 ha). Manual segmentation (Section 2.3.3) and ground referencing was used to build a reference spectral signature database and species-specific allometric models. Inventory data (Section 2.4.2) were then paired with the automatically segmented (Section 2.4.1) crowns based on size and geolocation congruence.

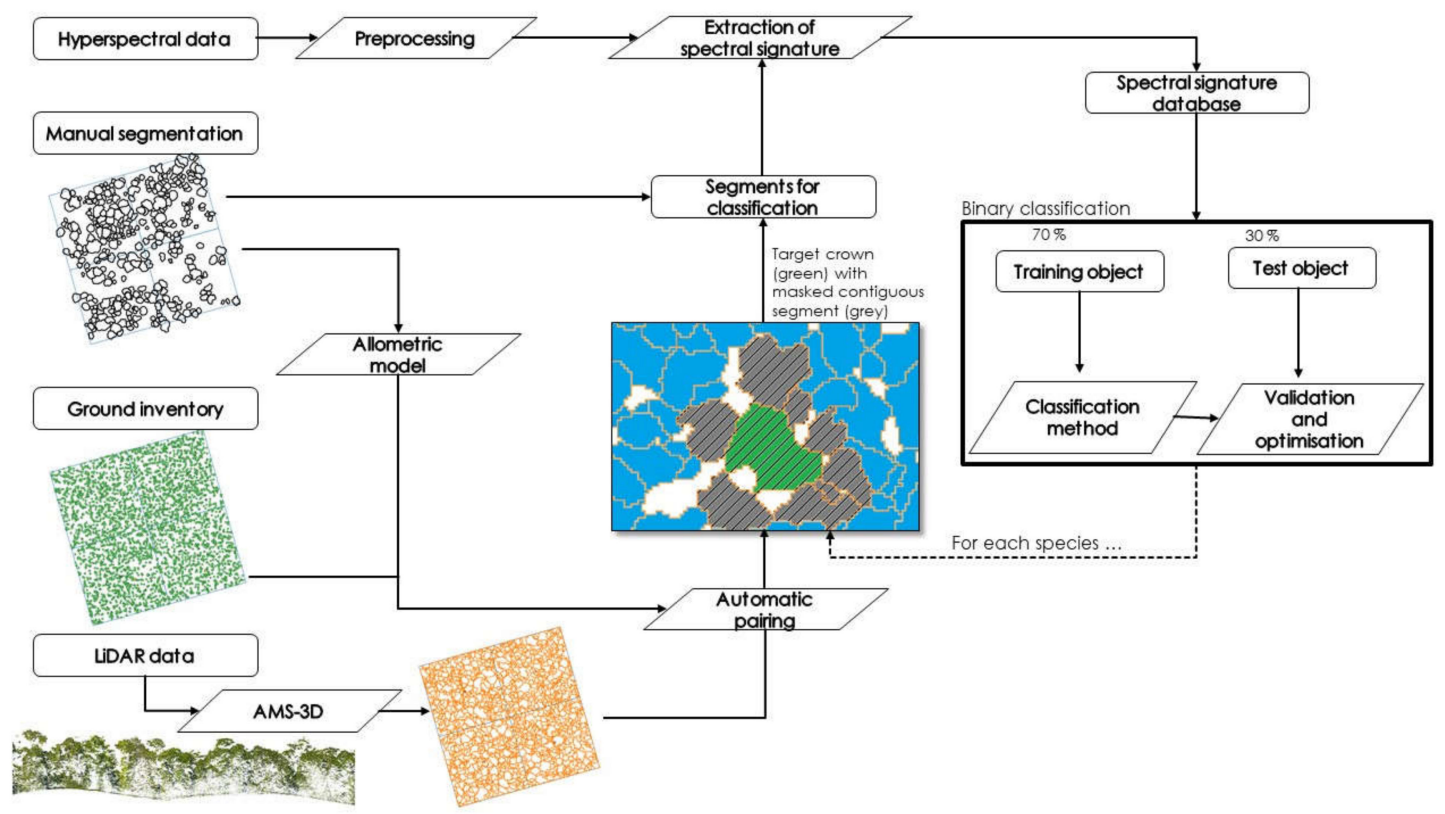

Figure 1. General methodological outline illustrated for a sample plot. The inventory data (green points) are paired with the automatically segmented crown (orange outline). Pairing is based on an allometric model developed from manually segmented crowns (black outline). In the segmented and colorized image, the green segment is one potential crown of the focal species; in grey, the neighbouring crowns that are also masked to make sure all pixels of the focal class are removed (striped segments) from the data set; in blue, the crowns preserved. 
The spectral signature database was used to train the binary classifiers, developed for each focal species (Section 2.5). The automatically delineated and labeled segments were used to mask the focal species across the whole area of the permanent plots to ensure a high level of purity of the non-focal class. To ensure that the non-focal class contained as few pixels as possible from the focal class, we considered a buffer around the crowns determined by the automatic assignment as belonging to the focal class. All contiguous segments and the segment itself were excluded from the training and testing sets (Figure 1).

\subsection{Remote Sensing Data}

\subsubsection{Hyperspectral Imaging}

Imaging spectroscopy data was acquired with a Hyspex VNIR-1600 and a Hyspex SWIR-384 (Hyspex NEO, Skedsmokorset, Norway) sensor. The VNIR-1600 sensor covers the range from $414 \mathrm{~nm}$ to $1000 \mathrm{~nm}$ with 160 spectral bands and a spectral sampling distance of $3.64 \mathrm{~nm}$. The SWIR-384 sensor covers the range from $1000 \mathrm{~nm}$ to $2500 \mathrm{~nm}$ with 288 spectral bands and a spectral sampling distance of $5.45 \mathrm{~nm}$. The entire spectral range of the VNIR sensor was used. The information acquired in the SWIR domain is sensitive to atmospheric water absorption, so the spectral information corresponding to the low signal-to-noise ratio domains was discarded. Finally, the following spectral windows were kept: for the SWIR domain: $1009 \mathrm{~nm}$ to $1318 \mathrm{~nm}, 1454 \mathrm{~nm}$ to $1796 \mathrm{~nm}$ and $1964 \mathrm{~nm}$ to $2458 \mathrm{~nm}$. Hence, 195 SWIR bands were retained. The King Air B200 airplane flew at an average altitude of $920 \mathrm{~m}$. The flight took place on a cloudless day (from 15:00 to 17:00, solar time) on the 19th September 2016. Images were orthorectified and georeferenced with the PARGE software [31] using the canopy DSM (digital surface model) produced from the LiDAR point cloud (see next section). The DSM was created from the point cloud by selecting point of maximum height on a 1-m resolution grid. The spatial resolutions of the VNIR and SWIR images were $1 \mathrm{~m}$ and $2 \mathrm{~m}$ respectively. In order to merge the data without degrading the spatial resolution of the VNIR imagery, we resampled the SWIR imagery at $1 \mathrm{~m}$ using the nearest neighbor method. In addition, the fields of view of the two sensors are not identical $\left(17^{\circ}\right.$ and $\left.16^{\circ}\right)$. We constrained the spectral information to the narrowest field of view corresponding to the one of the SWIR sensor. In the end, we obtained VSWIR imagery covering the entire spectrum ( $414 \mathrm{~nm}$ to $1963 \mathrm{~nm}$ ) corresponding to 355 bands. Spectral information used to train the species classifiers was extracted from flight lines rather than from a mosaic, as it was previously shown to be more effective [22]. Although the training was carried out on the flight lines, the prediction was done on the mosaic where the pixels with viewing angle closest to vertical were kept ("center cropped" option of PARGE software [32]).

Atmospheric correction was applied using ATCOR-4 software [31]. The water vapor was retrieved using the APDA (atmospheric pre-corrected differential absorption) algorithm. The aerosol optical thickness (AOT) represents the amount of aerosols in the entire column of the atmosphere. It was considered constant. Non-vegetated pixels were identified based on NDVI (normalized difference vegetation index) thresholding, following recommendations for wavelength selection given in [33].

$$
N D V I=\frac{\lambda_{774}-\lambda_{676}}{\lambda_{774}+\lambda_{676}}
$$

Pixels with NDVI values higher than 0.4 were considered vegetation. Then, we applied a spatial mean filtering and a spectrum normalization by the mean as described in [22]. The illumination ratio was used to remove pixels with a scaled shadow fraction value higher than 0.6.

\subsubsection{LiDAR Data and RGB Imagery}

Airborne laser scanning data and RGB imagery were acquired during the same flight as the hyperspectral data. The LiDAR system was an LMS Q780 RIEGL operated with the following characteristics: a scan frequency of $400 \mathrm{kHz}$, a scan angle of $+/-30^{\circ}$. Neighbouring strips overlapped 
by $90 \%$. Final mean pulse density was 33 pulses $\cdot \mathrm{m}^{-2}$. In addition, RGB (red, green, blue) imagery was acquired during the same flight using an iXu 180 Phase One camera. The final spatial resolution of the RGB orthorectified mosaic was $10 \mathrm{~cm}$.

\subsubsection{Ground Reference Data}

A field survey was conducted to build a large ground reference dataset distributed over 56 of the 76 plots monitored on the study site $(87.5 \mathrm{ha})$. Easily discernible crowns were first delineated manually based on the canopy height model ( $\mathrm{CHM})$, derived from LiDAR data with the help of the high-resolution RGB mosaic. The correct delineation of these ITCs was then validated in the field and the corresponding species ascertained. The 20 most abundant species in the delineated ITC dataset represented 1297 ITCs with a minimum of 24 individuals per species. Another 949 crowns were delineated, corresponding to 226 species. In total, the labeled database contained 2246 trees (Table 1). Most crowns were imaged twice by hyperspectral sensors because of the overlapping flight lines. The normalized mean spectra and its standard deviation for the most abundant tree species is illustrated in Figure 2.

Table 1. List of target species, and corresponding number of crowns and total number of pixels retained for analysis (each crown was imaged twice, but some pixels were removed due to low illumination or NDVI values). Sample representation refers to the proportion of manually segmented crowns of a given species. Mean crown area followed by standard deviation in brackets. Commercial species are underlined.

\begin{tabular}{|c|c|c|c|c|}
\hline Species (Acronyms) & $\begin{array}{l}\text { Number of } \\
\text { Crowns }\end{array}$ & $\begin{array}{l}\text { Number of } \\
\text { Pixels }\end{array}$ & $\begin{array}{c}\text { Mean Crown Area } \\
\left(\mathrm{m}^{2}\right)(\mathrm{SD})\end{array}$ & $\begin{array}{c}\text { Sample } \\
\text { Representation } \\
(\%)\end{array}$ \\
\hline Qualea rosea (Q.r.) & 206 & 27,828 & $109.5(59.4)$ & 9.2 \\
\hline Pradosia cochlearia (P.c.) & 164 & 38,349 & $142.3(122.5)$ & 7.3 \\
\hline Eschweilera sagotiana (E.s.) & 139 & 12,559 & $49.1(29.0)$ & 6.2 \\
\hline$\overline{\text { Dicorynia guianensis }}$ (D.g.) & 108 & 18,589 & $102.7(66.8)$ & 4.8 \\
\hline Eperua falcata (E.f.) & 106 & 15,355 & $71.7(41.3)$ & 4.7 \\
\hline Eperua grandiflora (E.g.) & 74 & 10,859 & $87.3(46.2)$ & 3.3 \\
\hline Recordoxylon speciosum (R.s.) & 69 & 7944 & $69.6(26.2)$ & 3.1 \\
\hline Tachigali melinonii (T.m.) & 51 & 6745 & $106.2(67.1)$ & 2.3 \\
\hline Couratari multiflora (C.m.) & 49 & 4850 & $55.1(33.8)$ & 2.2 \\
\hline Licania alba (L.a.) & 46 & 3894 & $47.0(18.4)$ & 2.0 \\
\hline Symphonia sp.1 (S.s.) & 34 & 3355 & $50.2(20.1)$ & 1.5 \\
\hline Vouacapoua americana (V.a.) & 34 & 3218 & $65.4(34.0)$ & 1.5 \\
\hline Sextonia rubra (S.r.) & 32 & 4070 & $118.5(99.3)$ & 1.4 \\
\hline Tapura capitulifera (T.c.) & 32 & 1224 & $30.5(12.2)$ & 1.4 \\
\hline Licania heteromorpha (L.h.) & 27 & 1437 & $40.3(21.7)$ & 1.2 \\
\hline Moronobea coccinea (M.c.) & 27 & 3355 & $68.8(36.7)$ & 1.2 \\
\hline Inga alba (I.a.) & 26 & 3846 & $81.3(58.7)$ & 1.2 \\
\hline Goupia glabra (G.g.) & 25 & 4998 & $133.7(77.3)$ & 1.1 \\
\hline Bocoa prouacensis (B.p.) & 24 & 2375 & $54.9(35.8)$ & 1.1 \\
\hline Jacaranda copaia (J.c.) & 24 & 1705 & $40.4(22.7)$ & 1.1 \\
\hline Others & 949 & 84,713 & $80.8(71.6)$ & 42.3 \\
\hline
\end{tabular}

In the 20 plots where no manual segmentation of ITC was done, 532 species were recorded for a total of 19,379 trees. 


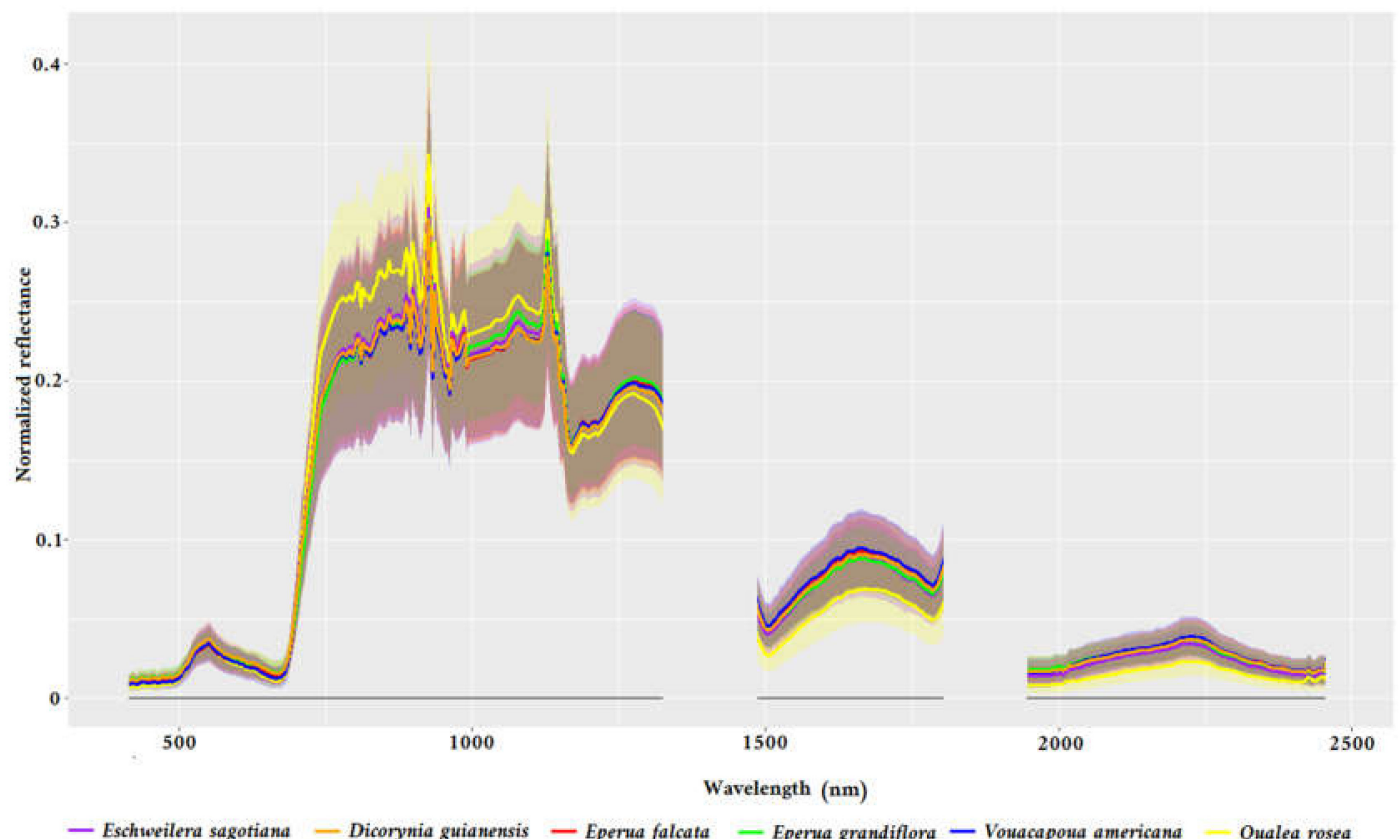

Figure 2. Normalized mean reflectance spectra (and standard deviation) for six focal species estimated on manually segmented crowns.

\subsection{Automatic Segmentation Method}

\subsubsection{AMS-3D Method}

We applied AMS-3D [34] to the LiDAR data for ITCs segmentation. The AMS-3D algorithm considers the point cloud as a multi-modal 3D distribution where each mode corresponds to the location of a tree crown. To find the modes, a Pollock function was used as bandwidth [35], with parameters changing with points' height to allow higher crowns to be bigger [34]. Points converging to the same mode were attributed the same ITC. The 3D clusters corresponding to each crown were then projected vertically to obtain polygons. The point cloud segmentation was conducted with the Computree platform (http://computree.onf.fr/), and the projection with the R package lidR [36].

\subsubsection{Correspondence between ITC and Inventory Data}

The automatically segmented crowns were then paired with the inventory data, using a pairing algorithm based on allometric relation and distance between the crown and the stem [27]. First, using data from the manually segmented crowns, we modelled each tree DBH as a function of crown diameter, height and taxon:

$$
\begin{gathered}
\ln \left(D B H_{i}\right)=\alpha_{s p_{i}}+\beta_{s p_{i}} \ln \left(H_{i} \times C D_{i}\right)+\varepsilon \\
\varepsilon \sim \mathcal{N}\left(0, \sigma_{i}^{2}\right)
\end{gathered}
$$

where $D B H_{i}$ is the $\mathrm{DBH}(\mathrm{cm})$ of tree $i$ of species $s p_{i}, H_{i}$ is its height, $C D_{i}$ its crown diameter, and $\varepsilon$ the error term. We then computed the distance between each manual segmented crown and all trunks of the inventory, computed the distance ranking of the trunk associated with the crowns, and fitted an exponential distribution on the ranks:

$$
d_{i, j}=\alpha e^{-\alpha r_{i, j}}
$$

where $r_{i, j}$ is the rank of tree $\mathrm{j}$ associated with crown $i$, and $\alpha$ is the parameter of the exponential distribution. Then, we developed an algorithm to optimally pair a crown with a tree from the inventory using the model previously parameterized. This algorithm takes two types of information into account: 
(i) the distance between the crown center (computed as the 2D-centroid of crown projection) and the trunk location in the inventory should be close, and (ii) the tree should obey the allometric relation between the crown size and the trunk diameter. We considered those two rules to apply independently, neglecting a possible dependency of crown trunk distance on tree size. The pairing algorithm pairs each crown with the tree with highest:

$$
p_{i, j}=d_{i, j} \cdot g_{i, j}
$$

where $g_{i, j}$ is the density function of the allometric model. Stems were ordered by decreasing DBH, and they were paired one after another in that order, with the segmented crown having the largest $d_{i, j}$ in the neighbourhood of the stem $(15 \mathrm{~m})$. When a crown was allocated to a stem, it was no longer available for others. Details of the algorithm can be found in [27].

\subsection{Classification Method}

We compared three classification methods for tree species identification: linear discriminant analysis (LDA), regularized discriminant analysis (RDA) and logistic regression (LR). We used the python language and the sklearn library [37]. The optimization of hyperparameters for the LR required considerable computing power. We used a Singularity container [38] and ran the code on a cluster of computers.

The LDA classification algorithm is well adapted to classification problems in high-dimension feature spaces provided that the number of observations is larger than the number of features in the least abundant class [39]. The principle of LDA consists in calculating new variables called discriminating canonical variables as linear combinations of the initial variables. It is calculated to maximize the ratio of the inter-group variance to the intra-group variance.

RDA is a compromise between LDA and quadratic discriminant analysis (QDA). QDA is a variant of LDA, the former being better adapted for non-linear separation. LDA assumes multivariate normal distribution of features with a common covariance matrix and different mean vector for each class. As shown by [40], LDA is not sensitive to the normal distribution assumption. Nevertheless, when the assumption of common covariance matrix is not satisfied, the individual covariance matrix for each group should preferably be estimated. This specific step characterizes QDA. The discriminating boundaries of the QDA are quadratic curves. The intermediate method between the two gives the RDA method proposed by [41] and makes it possible to regularize group covariance matrices, while preserving its performance in multi-dimensionality [42].

The assumptions of multivariate normality and equal variance-covariance matrices between groups are required before proceeding with LDA. On the contrary, in LR, these assumptions are not made. The authors of [43] showed in a bivariate case that in binary classification LR would be more efficient as soon as the normality assumption would be violated. A regularization term penalizing large values of the parameters was considered to avoid possible overfitting during the training step. A penalty parameter controlling the relative cost of errors occurring in the two classes was also tuned. We used a grid search to find the best combination of hyper-parameters $C$ (regularization) and $w_{C}$ (relative focal class weight) over the values $C\left\{\mathrm{e}^{0}, \mathrm{e}^{1}, \mathrm{e}^{2}, \ldots, \mathrm{e}^{6}\right\}$ and $w_{\mathcal{c}}\{1,2, \ldots, 10\}$. In case of bias (impure non-focal class), we used the criterion of [29], otherwise we used the F-measure metric (see below).

\subsubsection{Classifier Evaluation Criteria}

To assess the reliability of the binary classifier, the F-measure was the chosen accuracy measurement. It relies on the estimation of the precision and recall of the class of interest. F-measure was used instead of accuracy due to the difference in proportion between the classes. The precision is the number of correct positive results divided by the number of all positive results returned by the classifier, 
and the recall is the number of correct positive results divided by the number of all relevant samples (all samples that should have been identified as positive).

$$
\begin{aligned}
\mathrm{F}-\text { measure } & =\frac{2 \times \text { precision } \times \text { recall }}{\text { precision }+ \text { recall }} \\
\text { Precision } & =\frac{\sum \mathrm{TP}}{\sum(\mathrm{TP}+\mathrm{FP})} \\
\text { Recall } & =\frac{\sum \mathrm{TP}}{\sum(\mathrm{TP}+\mathrm{FN})}
\end{aligned}
$$

TP, FP and FN refer to true positive, false positive and false negative, respectively.

For comparison between LDA, RDA and LR, we used the exact same randomly sampled training and testing sets.

\subsubsection{Optimization Step}

All classifiers used in this study output a probability for a pixel of belonging to the focal class, which is defined by the maximum likelihood. The threshold used for assignment to the focal class can be refined by using a specified criterion, to improve the classification performance. We used different criteria for the standard (unbiased) case and when the non-focal class was impure. In the standard case, we sought to maximize the pixel level F-measure. When dealing with the mislabeled non-focal class (i.e., when the non-focal class contained pixels of the focal class), true precision was unknown, so we sought to maximize the following quantity [29]:

$$
\frac{\text { Recall }^{2}}{P(f(x)=1)}
$$

where the Recall is recall of the accuracy and $P[f(x)=1]$ is the probability that a sample is classified in the focal class.

\subsection{Experimental Set-Up}

We present four different experiments. All classifiers considered in this study were binary classifiers; i.e., a particular focal species is classified against a large set of non-focal species. As a rule, we separated the data into $70 \%$ of the crowns used for the training set and $30 \%$ for the test set (Figure 3 ) repeating the operation 30 times. We provide the mean and the standard deviation of the F-measure.

We first compared classification performances obtained when using spectral information from either VNIR or VSWIR on the 20 most abundant species only (Experiment 1). Then, we explored how the performance of the classifier would be affected by gradually increasing the number of species among which our focal species was retrieved (Experiment 2). In a third experiment, we explored the sensitivity of the classifiers to different types of errors affecting the training data (labeling errors) (Figure 3, Experiment 3). In a final test (Experiment 4), we predicted the basal area of focal species per 1.56 ha plot from the hyperspectral data. 


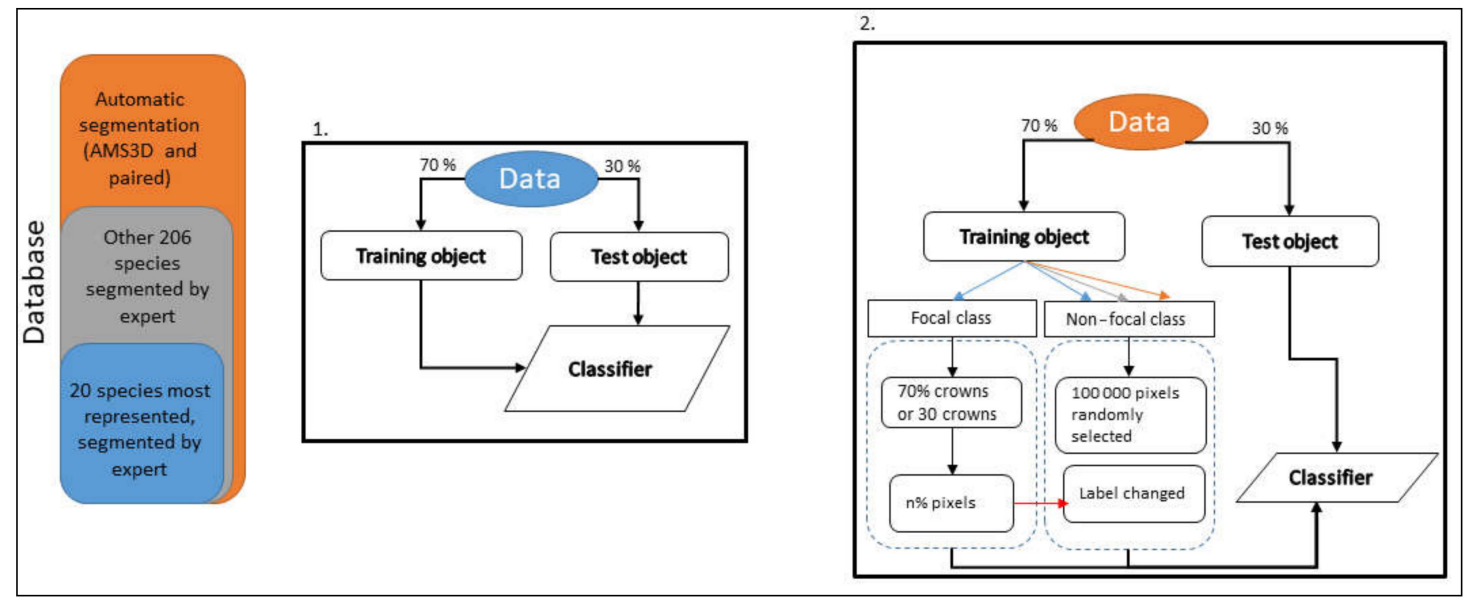

Figure 3. Nested datasets are used as illustrated in the leftmost chart. Flowchart 1 refers to Experiment 1. Flowchart 2 illustrates how classifiers were penalized by contamination of the non-focal class (Experiment 3).

\subsubsection{Experiment $1-$ VNIR versus VNIR+ SWIR}

We assessed the effectiveness of adding SWIR bands to the VNIR spectrum. We used manual segmentation data and we selected the 20 most abundant tree species (Figure 3, 1). The same pixels were used to build training and test sets $(70 \%-30 \%)$ for VNIR and VSWIR data. For this first experiment, none of the three classification methods were subject to secondary optimization.

\subsubsection{Experiment 2-Increasing Background Spectral Diversity}

The same 20 focal species were considered for this experiment, but we gradually added more species to the non-focal class. We first added the crowns of the most abundant species present in the manually segmented crowns database, up to 99 different species. We then added all the remaining crowns from the manual segmentation database (each crown being the sole representative of its species) in arbitrary order. Thereby, the 364 different species were opposed to each of the 20 species alternately. For this first experiment, LDA was used, without an optimization step.

\subsubsection{Experiment 3-Effect of Noise in the Training Data}

In an operational case, the inventory effort will likely be focused on few target species. Thus, the other non-focal species will not be systematically inventoried. Therefore, to train the classifier, the non-focal species class will be represented by a random selection of pixels over the entire study area (excluding crowns known to belong to the focal species). However, the probability for a pixel of the focal class of being selected and contributing to the non-focal class is dependent on the distribution of this species in the study area, viewed at canopy level.

To assess the impact of a given level of mislabeling of the non-focal pixels, we artificially biased the learning data set (Figure 3, 2). We randomly selected 100,000 pixels from the background, excluding the focal species to create the training set for the non-focal species. We simulated three level of bias in the training data by successively replacing $1 \%, 2 \%$ and $5 \%$ of the pixels labeled as belonging to the non-focal class with pixels taken from crowns of the focal species class.

We also explored the potential impact of mislabeling of the focal pixels, reckoning that such errors may occur regardless of the efforts made in the field (identification errors, matching errors, etc.). We used Mahalanobis distance to detect outliers among the 20 most abundant species in the manually segmented crown database. For each species, we computed this multi-dimensional distance for each pixel, we then computed the mean Mahalanobis distance per crown. Crowns beyond two standard deviations were considered as pseudo-outliers and removed from the database. Binary 
classifications using all the information (including pseudo outliers) were then compared to those excluding pseudo-outliers.

Mahalanobis distance is a multi-dimensional distance measure between a point and a distribution. This distance $d(x)$ can also be defined as a dissimilarity measure between a vector and a mean vector from the same distribution:

$$
d(\vec{x})=\sqrt{(\vec{x}-\vec{u})^{T} \sum^{-1}(\vec{x}-\vec{u})}
$$

where $x$ is a spectrum, $u$ the mean spectrum, $\Sigma$ is the variance-covariance matrix.

\subsubsection{Experiment 4-Predicting Basal Area per Species per Plot}

The ground inventory data comprised 76 plots of 1.56 hectares. For each plot, we compared the canopy surface predicted per species (at crown and pixel level) by the best-performing classification method and the basal area of the species using a linear regression. The learning step used all the information on the focal species which was available in the manually segmented crown database to build the focal class and 100,000 pixels randomly selected from the same 56 plots. Hence, 20 plots (c. $25 \%$ of the area) were set aside to be used for independent validation. The learning step used 100,000 pixels from flight lines, while the prediction was realized on the mosaic.

We compared prediction of the three classifiers applied with and without an optimization step and with or without majority vote at crown level. The majority vote rule was applied to decide on the species label to be assigned to ITCs, which corresponded to a filling rate higher than $50 \%$ of the pixels. We present the results obtained with the LDA only. The basal area considered here is the basal area of all trees with $\mathrm{DBH}$ greater than $10 \mathrm{~cm}$. It may be noted that smallest trees will not be visible in the areal imagery.

\section{Results}

\subsection{Experiment 1}

The combination of VNIR and SWIR information strongly improved the performances of all classifiers compared to VNIR information only, with an increase in F-measure of $23.8 \%, 27.3 \%$ and $19.4 \%$ for LDA, RDA and LR respectively. The contribution of SWIR was very important for all species. The difference between LDA and RDA was not significant in this case. All species were rather well identified (F-measure never lower than 59\%). LR did not outperform LDA nor RDA.

Moderate differences in performance were observed between classifiers when only the VNIR information was used. LR performed slightly better than the other two methods except for Eschweilera sagotiana (70\% vs. $79 \%$ ) and RDA appeared to perform slightly worse, particularly at pixel level (Appendix A). The change from pixel to object level was confirmed to be very beneficial. LDA gained the most from the majority vote, with an increase of $15.5 \%$ in F-measure using the complete VSWIR information (Table 2).

Table 2. Comparison of the F-measure at object level (and standard deviation) obtained after classification with the three methods when either VNIR or VSWIR information are used. Commercial species are underlined. The best prediction for each species with either VNIR or VSWIR information is in bold.

\begin{tabular}{ccccccc}
\hline \multirow{2}{*}{ Species } & \multicolumn{3}{c}{ VNIR } & \multicolumn{3}{c}{ VSWIR } \\
\cline { 2 - 7 } & LDA & RDA & LR & LDA & RDA & LR \\
\hline B.p. & $25.4( \pm 11.6)$ & $22.3( \pm 8.5)$ & $\mathbf{2 6 . 4 ( \pm 7 . 2 )}$ & $66.9( \pm 11.3)$ & $\mathbf{8 3 . 3 ( \pm 1 0 . 4 )}$ & $61.0( \pm 18.0)$ \\
C.m. & $66.7( \pm 13.2)$ & $64.8( \pm 13.5)$ & $\mathbf{6 7 . 5 ( \pm 1 1 . 0 )}$ & $75.0( \pm 10.7)$ & $67.9( \pm 9.9)$ & $\mathbf{7 7 . 0}( \pm 8.4)$ \\
D.g. & $61.2( \pm 4.5)$ & $61.3( \pm 4.7)$ & $\mathbf{6 9 . 2 ( \pm 7 . 0 )}$ & $88.6( \pm 2.5)$ & $86.3( \pm 3.6)$ & $\mathbf{9 0 . 3}( \pm 2.4)$ \\
E.f. & $\mathbf{4 6 . 9}( \pm 5.5)$ & $7.3( \pm 2.5)$ & $29.6( \pm 9.6)$ & $70.0( \pm 5.8)$ & $72.9( \pm 8.2)$ & $\mathbf{7 3 . 9 ( \pm 6 . 7 )}$ \\
\hline
\end{tabular}


Table 2. Cont.

\begin{tabular}{|c|c|c|c|c|c|c|}
\hline \multirow{2}{*}{ Species } & \multicolumn{3}{|c|}{ VNIR } & \multicolumn{3}{|c|}{ VSWIR } \\
\hline & LDA & RDA & LR & LDA & RDA & LR \\
\hline E.g. & $63.1( \pm 6.4)$ & $61.8( \pm 7.4)$ & $79.4( \pm 5.0)$ & $82.1( \pm 5.3)$ & $87.6( \pm 4.4)$ & $89.7( \pm 3.6)$ \\
\hline$\overline{E . S .}$ & $79.0( \pm 3.3)$ & $72.8( \pm 5.3)$ & $70.6( \pm 7.3)$ & $89.6( \pm 2.8)$ & $89.3( \pm 1.9)$ & $86.4( \pm 2.1)$ \\
\hline$\overline{G . g .}$ & $44.3( \pm 8.9)$ & $63.3( \pm 12.1)$ & $67.6( \pm 12.9)$ & $84.1( \pm 7.3)$ & $83.9( \pm 12.0)$ & $80.4( \pm 12.7)$ \\
\hline I.a. & $44.4( \pm 14.2)$ & $49.4( \pm 15.6)$ & $62.7( \pm 17.2)$ & $77.6( \pm 10.0)$ & $76.3( \pm 8.5)$ & $66.0( \pm 16.0)$ \\
\hline J.c. & $58.4( \pm 16.7)$ & $59.2( \pm 12.6)$ & $57.1( \pm 16.6)$ & $59.2( \pm 19.1)$ & $58.2( \pm 18.1)$ & $70.2( \pm 16.8)$ \\
\hline L.a. & $55.9( \pm 10.0)$ & $62.9( \pm 10.7)$ & $62.6( \pm 11.4)$ & $78.1( \pm 4.5)$ & $79.6( \pm 9.5)$ & $74.6( \pm 9.1)$ \\
\hline L.h. & $22.2( \pm 8.0)$ & $16.7( \pm 0.0)$ & $20.0( \pm 0.0)$ & $65.2( \pm 11.3)$ & $60.7( \pm 13.7)$ & $49.0( \pm 14.6)$ \\
\hline M.c. & $64.5( \pm 11.4)$ & $52.7( \pm 14.3)$ & $64.1( \pm 13.3)$ & $82.8( \pm 10.9)$ & $74.7( \pm 17.4)$ & $79.7( \pm 12.7)$ \\
\hline P.c. & $80.5( \pm 4.2)$ & $83.6( \pm 3.8)$ & $88.4( \pm 3.3)$ & $93.5( \pm 1.9)$ & $93.6( \pm 1.9)$ & $94.1( \pm 1.6)$ \\
\hline Q.r. & $94.8( \pm 1.6)$ & $94.6( \pm 1.5)$ & $95.6( \pm 1.2)$ & $96.9( \pm 1.1)$ & $96.2( \pm 1.4)$ & $97.2( \pm 1.1)$ \\
\hline$\overline{R . s .}$ & $84.9( \pm 6.0)$ & $81.4( \pm 5.0)$ & $90.0( \pm 4.7)$ & $91.4( \pm 3.3)$ & $87.1( \pm 6.1)$ & $90.6( \pm 3.8)$ \\
\hline S.r. & $55.0( \pm 9.2)$ & $50.6( \pm 14.5)$ & $53.7( \pm 13.2)$ & $77.6( \pm 11.5)$ & $82.9( \pm 8.4)$ & $85.2( \pm 7.3)$ \\
\hline S.s. & $24.0( \pm 0.0)$ & $0.0( \pm 0.0)$ & $11.3( \pm 0.0)$ & $64.0( \pm 11.7)$ & $68.9( \pm 12.1)$ & $50.5( \pm 13.7)$ \\
\hline T.m. & $73.3( \pm 7.7)$ & $79.2( \pm 6.0)$ & $84.1( \pm 5.6)$ & $93.5( \pm 4.1)$ & $93.3( \pm 4.3)$ & $93.4( \pm 4.1)$ \\
\hline T.c. & $35.4( \pm 8.7)$ & $17.1( \pm 4.0)$ & $38.2( \pm 14.1)$ & $82.6( \pm 8.9)$ & $72.7( \pm 11.8)$ & $83.5( \pm 9.8)$ \\
\hline V.a. & $48.7( \pm 13.8)$ & $52.8( \pm 13.7)$ & $43.0( \pm 14.7)$ & $85.1( \pm 8.3)$ & $83.8( \pm 10.0)$ & $77.1( \pm 10.1)$ \\
\hline Mean $\overline{\text { F-measue }}$ & 56.4 & 52.7 & 59.1 & 80.2 & 80.0 & 78.5 \\
\hline
\end{tabular}

\subsection{Experiment 2}

We gradually added crowns from new species to increase the spectral variability of the non-focal class. We used an LDA binary classifier to retrieve each of the 20 most abundant species. No optimization was applied. We present the results at object level (following majority vote).

The overall trend in Figure 4 highlights that increasing the number of species degraded the classifier's performance. Some species were highly affected (e.g., Eschweilera sagotiana); others were only slightly affected (e.g., Qualea rosea). Increasing the number of species from 99 to 364 significantly affected discrimination of all target species. F-measure for Qualea rosea, the best-identified species, decreased from $88.6 \%$ to $84.9 \%$, a loss of about $4 \%$ points.

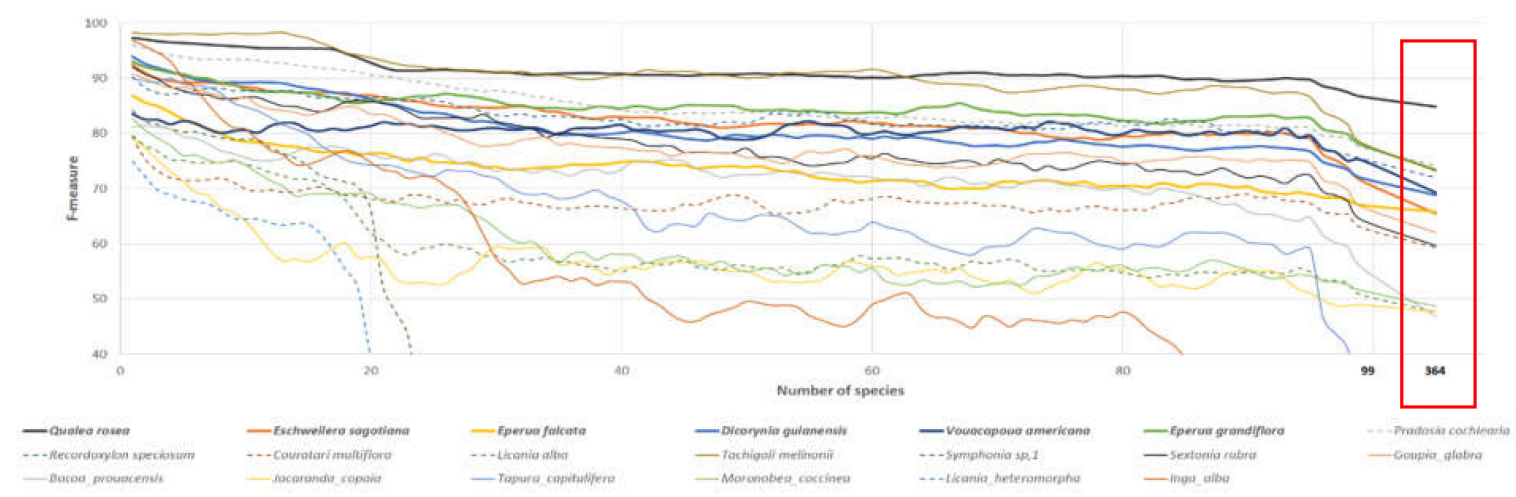

Figure 4. Evolution of species discrimination by successive addition of new species. F-measure value is smoothed using a five-step moving average, except after the 99th species when all remaining species were added at once (red box). Commercially valuable species are plotted in bold line.

The F-measure value for the species Licania alba, Licania heteromorpha and Inga alba declined sharply with the added species. In these cases, the focal species was well retrieved (the recall was higher than $70 \%$ ), but the precision was very low (a lot of pixels were wrongly predicted to belong to the focal class). 


\subsection{Experiment 3 -Exploring the Impact of Training Set Impurity}

To evaluate the impact on the classification performance of mislabeled pixels in the non-focal class, we applied different levels of contamination bias $(1 \%, 2 \%$ and $5 \%)$.

\subsubsection{Low Level of Impurity (All Species)}

We first examined to what degree the different classification methods were affected by a low level of impurity of the non-focal class, and whether optimizing the pixel threshold based on the criterion proposed by [29] could mitigate this bias.

A noise of $1 \%$ had no significant effect on the identification of species, whether an optimization step was used or not (Table 3). When no optimisation was applied, LDA was outperformed by the other two methods for most of the species. For some species, LR was more efficient (e.g., Pradosia cochlearia) while for other species (e.g., Sextonia rubra) RDA performed best. Once optimized, all methods performed on a par in this experiment.

Table 3. Object level F-measure (and its standard deviation in brackets) of species binary classifiers trained with $1 \%$ mislabeling of the non-focal class. Plain and optimized indicate whether an optimization step (selecting a threshold probability value) was applied to maximize either the F-measure ( $0 \%$ contamination) or the Lee and Liu 2003 criterion (1\% contamination). Standard deviation is given in Appendix B. The best prediction for each species and method is in bold.

\begin{tabular}{|c|c|c|c|c|c|c|c|c|c|c|c|c|}
\hline \multirow{3}{*}{$\begin{array}{c}\text { Bias } \\
\text { Species }\end{array}$} & \multicolumn{6}{|c|}{$0 \%$} & \multicolumn{6}{|c|}{$1 \%$} \\
\hline & \multicolumn{3}{|c|}{ Plain } & \multicolumn{3}{|c|}{ Optimized } & \multicolumn{3}{|c|}{ Plain } & \multicolumn{3}{|c|}{ Optimized } \\
\hline & LDA & RDA & LR & LDA & RDA & LR & LDA & RDA & LR & LDA & RDA & LR \\
\hline B.p. & $35.8( \pm 10.3)$ & $57.7( \pm 12.4)$ & $37.5( \pm 15.5)$ & 65.4 & 57.5 & 42.1 & 36.4 & 58.5 & 43.4 & 64.3 & 56.2 & 43.0 \\
\hline C. $m$. & $68.3( \pm 10.8)$ & $64.7( \pm 10.1)$ & $68.0( \pm 10.5)$ & 69.8 & 68.3 & 71.4 & 67.4 & 65.1 & 66.5 & 69.8 & 68.0 & 69.4 \\
\hline D.g. & $57.7( \pm 3.9)$ & $72.3( \pm 6.0)$ & $78.2( \pm 6.1)$ & 75.8 & 72.0 & 78.5 & 57.5 & 72.6 & 78.2 & 74.8 & 72.2 & 78.3 \\
\hline$\overline{E . f .}$ & $50.8( \pm 4.1)$ & $67.7( \pm 6.1)$ & $69.2( \pm 6.2)$ & 71.5 & 68.9 & 70.5 & 51.5 & 67.9 & 68.0 & 72.1 & 69.2 & 70.5 \\
\hline$\overline{E . g .}$ & $65.1( \pm 7.0)$ & $82.0( \pm 5.3)$ & $84.4( \pm 4.6)$ & 82.4 & 82.7 & 84.8 & 64.9 & 81.9 & 82.5 & 82.0 & 82.5 & 84.7 \\
\hline$\overline{E . s .}$ & $68.1( \pm 4.2)$ & $74.2( \pm 4.1)$ & $71.0( \pm 5.2)$ & 74.7 & 74.1 & 75.9 & 68.5 & 74.7 & 69.2 & 74.1 & 73.4 & 74.9 \\
\hline$\overline{G . g}$. & $62.5( \pm 12.6)$ & $73.4( \pm 11.5)$ & $76.4( \pm 12.5)$ & 74.5 & 73.5 & 77.3 & 62.8 & 72.6 & 74.8 & 74.5 & 74.4 & 75.0 \\
\hline I. $a$. & $38.3( \pm 11.5)$ & $42.3( \pm 12.7)$ & $38.5( \pm 11.6)$ & 43.0 & 41.0 & 41.4 & 38.9 & 42.7 & 36.6 & 43.0 & 41.4 & 40.9 \\
\hline J.c. & $50.7( \pm 19.7)$ & $51.4( \pm 16.8)$ & $52.4( \pm 17.1)$ & 50.9 & 49.3 & 53.1 & 52.2 & 49.0 & 51.6 & 51.5 & 50.4 & 52.6 \\
\hline L.a. & $41.6( \pm 8.7)$ & $56.3( \pm 10.8)$ & $53.9( \pm 10.5)$ & 56.6 & 54.4 & 62.3 & 41.9 & 56.8 & 48.5 & 57.0 & 54.7 & 59.7 \\
\hline L.h. & $25.6( \pm 8.9)$ & $43.6( \pm 11.0)$ & $22.8( \pm 8.1)$ & 44.0 & 34.2 & 25.5 & 26.5 & 43.5 & 23.5 & 46.6 & 33.7 & 26.0 \\
\hline M.c. & $58.5( \pm 13.8)$ & $55.5( \pm 16.9)$ & $60.0( \pm 14.5)$ & 56.3 & 54.9 & 62.7 & 58.6 & 56.1 & 56.5 & 55.4 & 56.2 & 61.7 \\
\hline P.c. & $69.5( \pm 4.5)$ & $77.1( \pm 4.9)$ & $85.9( \pm 3.6)$ & 77.6 & 77.0 & 84.3 & 69.6 & 78.0 & 85.8 & 78.2 & 77.4 & 84.0 \\
\hline Q.r. & $86.6( \pm 2.5)$ & $88.1( \pm 2.7)$ & $91.3( \pm 2.3)$ & 86.4 & 85.8 & 90.7 & 86.9 & 88.1 & 91.2 & 86.6 & 86.2 & 90.8 \\
\hline$\overline{R . s .}$ & $82.5( \pm 3.8)$ & $78.8( \pm 4.5)$ & $81.2( \pm 5.2)$ & 81.0 & 80.7 & 84.9 & 82.4 & 79.3 & 79.5 & 80.7 & 79.7 & 83.4 \\
\hline S.r. & $54.3( \pm 9.2)$ & $70.8( \pm 10.7)$ & $61.6( \pm 14.7)$ & 71.8 & 66.9 & 68.0 & 53.8 & 69.7 & 52.3 & 71.3 & 66.4 & 61.1 \\
\hline S.s. & $29.1( \pm 5.9)$ & $36.7( \pm 9.1)$ & $21.3( \pm 7.1)$ & 36.6 & 36.7 & 25.6 & 29.1 & 35.8 & 21.3 & 35.5 & 35.8 & 25.6 \\
\hline T.m. & $64.7( \pm 6.4)$ & $69.9( \pm 6.0)$ & $80.7( \pm 9.4)$ & 76.3 & 75.8 & 78.8 & 64.9 & 70.4 & 78.2 & 76.0 & 75.6 & 78.9 \\
\hline T.c. & $58.3( \pm 11.5)$ & $65.4( \pm 12.5)$ & $72.2( \pm 14.8)$ & 65.8 & 52.1 & 72.5 & 58.2 & 65.4 & 69.6 & 63.6 & 51.0 & 70.6 \\
\hline$\underline{\text { V.a. }}$ & $68.2( \pm 8.7)$ & $72.8( \pm 12.2)$ & $65.1( \pm 12.8)$ & 74.4 & 74.4 & 66.9 & 66.5 & 74.1 & 63.9 & 74.4 & 73.6 & 64.6 \\
\hline Average & 56.8 & 65.0 & 63.6 & 66.7 & 64.0 & 65.9 & 56.9 & 65.1 & 62.0 & 66.6 & 63.9 & 64.8 \\
\hline
\end{tabular}

\subsubsection{High Level of Impurity (Most Abundant Species)}

This analysis was restricted to the five most abundant species in order to explore the effect of high rates of contamination of the non-focal species, which required having sufficient focal pixels. Results are summarized in Figure 5.

A labeling error of 5\% did not affect LDA, with or without an optimization step. However, the optimization step was very beneficial in both cases. RDA was mildly affected by labeling error and not improved by optimization. LR classification method was much more impacted by a 5\% error level and the optimization only partially compensated for this. The average loss in F-measure was $11.8 \%$ (without optimization) and 6.7\% (with optimization). More complete results on the average F-measure, with or without an optimization step are provided in Appendix B, including results obtained for $2 \%$ bias. 


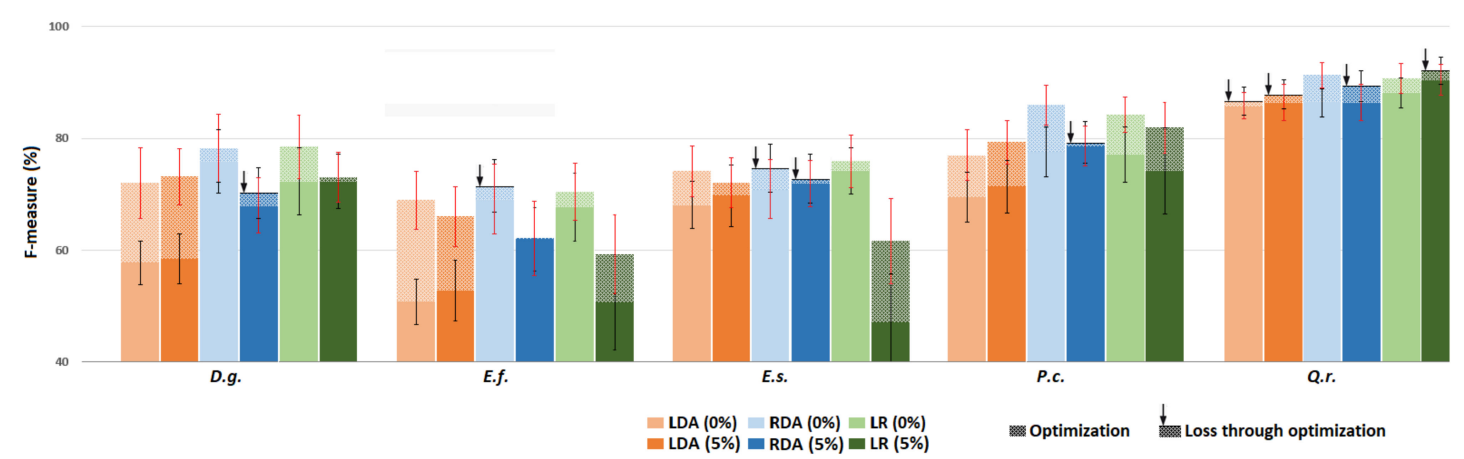

Figure 5. Object level F-measure (and its standard deviation) of species binary classifier trained with either $0 \%$ or $5 \%$ mislabeling of non-focal class. Paler color represents performance after applying an optimization step (see text). An arrow indicates cases when optimization decreased performance.

In summary, RDA appeared to be robust to high noise level even without optimization. LR was sensitive to noise even after including a modified optimization step criterion [29]. LDA performed very well, provided that an optimization step was included.

\subsubsection{High Level of Impurity-Smaller Focal Training Class}

To assess the impact of the size of the focal class on classification performance we reduced the number of crowns to 30 in the focal class while still considering 100,000 pixels randomly selected for the non-focal class. Only the five most abundant species were considered. Miss-labeled pixels were added to the non-focal class to achieve different levels of contamination (1\%, $2 \%$ and $5 \%)$. Results were almost undistinguishable from those obtained with larger training sets for the same level of bias (see Appendix C).

\subsubsection{Focal Class Purification}

Mean crown Mahalanobis distance (computed across pixels within species) was used to try to detect outliers (Figure 6). Only Licania alba and Bocoa prouacensis had no outliers (outliers being defined as crowns showing a mean Mahalanobis distance greater than two standard deviations from the mean of all crowns). The most heavily impacted species were Jacaranda copaia and Goupia glabra (see table in Appendix D). Overall, for the 1297 representatives in the 20 focal classes, 55 crowns were potential outliers. There was thus a global potential bias of the focal classes of $4.2 \%$ or 2844 unreliable spectra.

We examined all those potential outliers on high-resolution RGB imagery. In a few cases, those outliers could be related to particular features (illustrated in Appendix D): low illumination leaving very few pixels per crown after filtering, higher than average contribution of wood caused by partial leaflessness (especially for Eperua falcata), presence of liana in the crown. However, in $90 \%$ of the cases, no peculiarity was detected on high-resolution imagery. One cannot exclude that crown mislabeling occurred, but this could not be ascertained.

To evaluate the improvement achieved after removing potential outlier crowns, a Student test by species was performed on each metric at object level for the three classifiers (without the optimization step). We compared those metrics before and after removal of the potential outliers. The most impacted species were the Couratari multiflora (from $68 \%$ to $71.6 \%$ using LR) and Sextonia rubra (from $61.6 \%$ from $64.7 \%$ using LR) ( $p$-value $<0.01$ ). Recordoxylon speciosum (from $81.2 \%$ to $83.8 \%$ using LR) and Jacaranda copaia (from $50.7 \%$ to $59.2 \%$ using LDA) were less impacted ( $p$-value $<0.05$ ). The RDA method was the method least sensitive to the introduction of outliers. For more detail, see the table in Appendix D. 

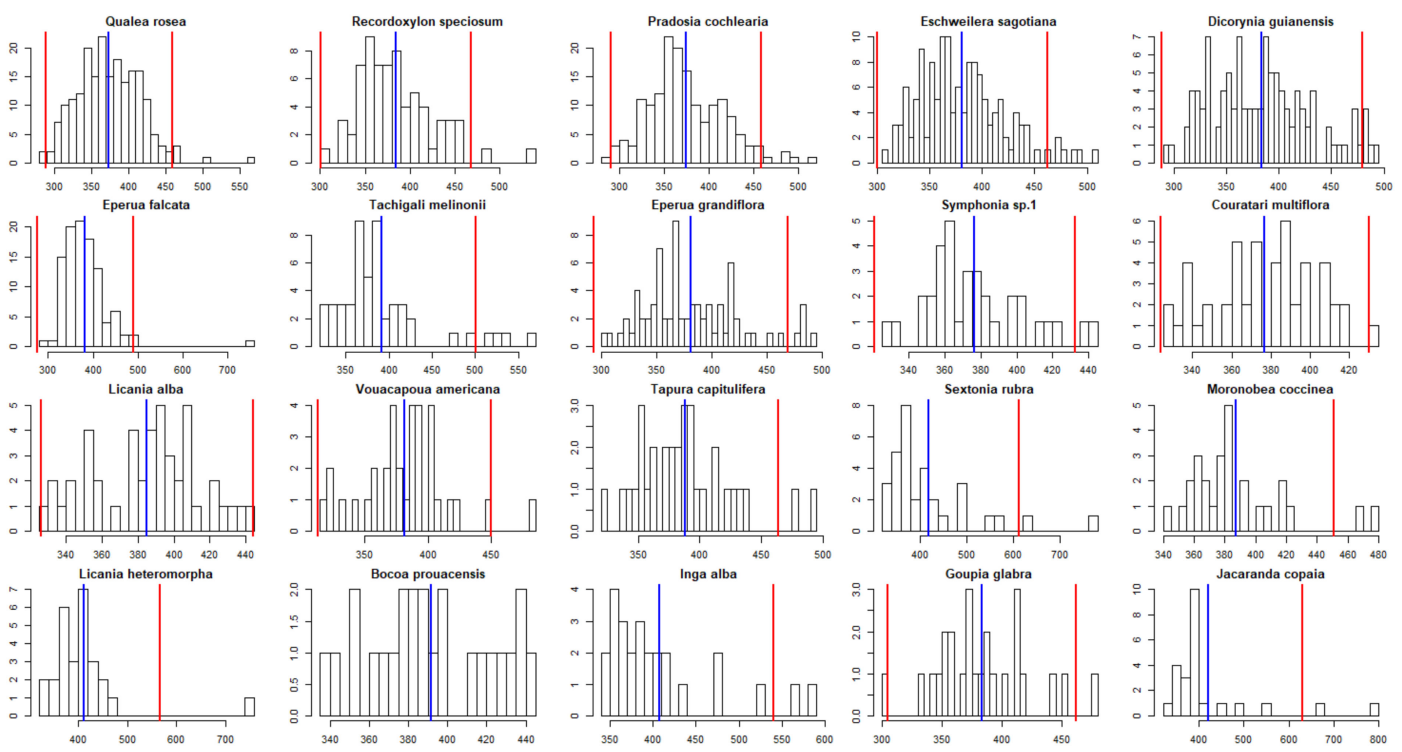

Figure 6. Within-species Mahalanobis distance (computed per crown). The blue line represents the mean of the Mahalanobis distance. The red lines represent the mean plus or minus two standard deviations.

\subsection{Experiment 4}

We related the recorded basal area per species per plot with the canopy area predicted to belong to the same species by the different classifiers. We used all the available crowns in our manual segments database to train the classifiers. For each focal species, we randomly selected 100,000 pixels to create the non-focal class for training the classifier. Results for LDA are reported in Figure 7 for the most abundant commercial species. Results for all other species are provided in Appendix E, Figure A3.

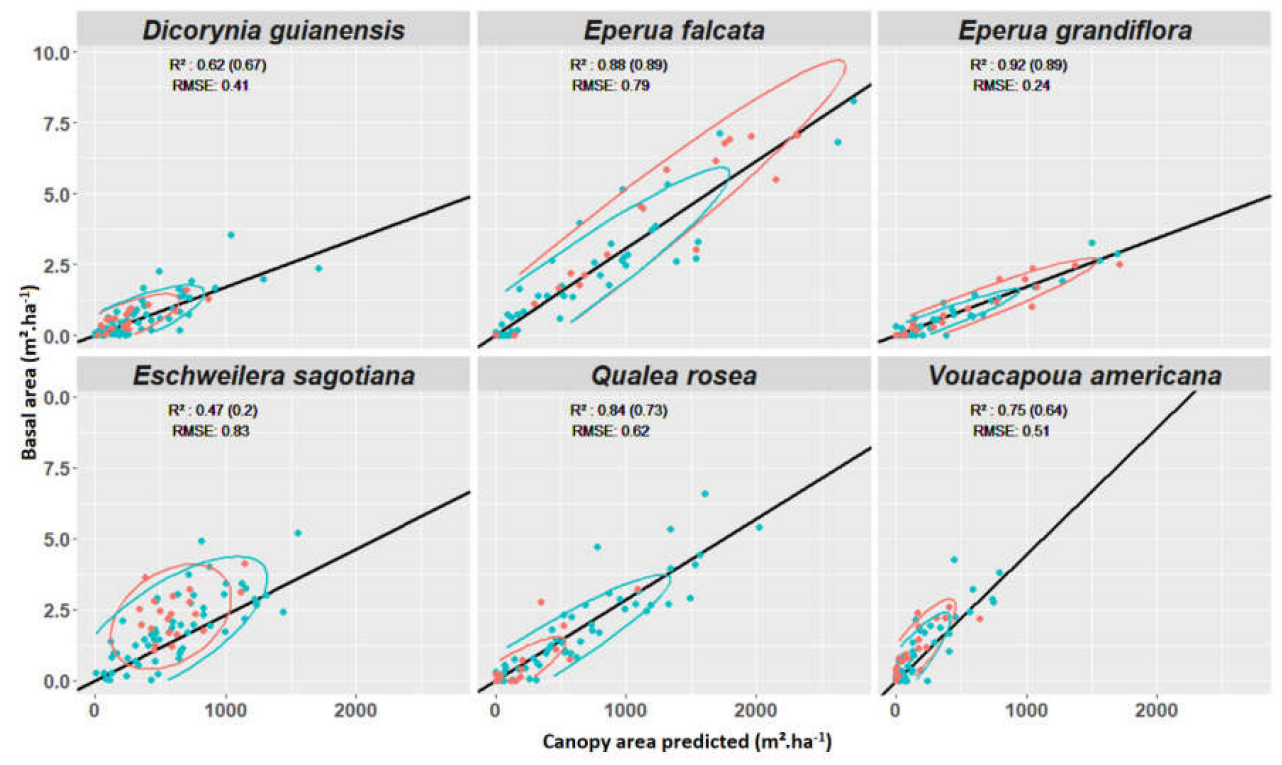

Figure 7. Relation between basal areal $\left(\mathrm{m}^{2} \cdot \mathrm{ha}^{-1}\right)$ and area predicted $\left(\mathrm{m}^{2} \cdot \mathrm{ha}^{-1}\right)$ using the optimized LDA. Plots not used for training are plotted in red and the R-squared for those observations given in brackets. The plot used for the training are in blue. Global R-squared values are given using all points (red and blue). In solid black line, linear regression based on all points passing through zero. The normal confidence ellipses are given, computed for each group points using the corresponding color (red or blue). 
As expected, the effectiveness of the classifier conditions the correlation between the predicted canopy area and the basal area. The mean linear correlation coefficient across species was $0.70(n=20$; Appendix F). Optimized LDA and RDA were the methods that provided the best average $\mathrm{R}^{2}$ both at pixel and object level (not shown).

In addition, we compared the slope of the relations across species. We used a linear model without intercept. While species effect was significant overall ( $p<0.01$, e.g., Eperua grandiflora vs. Eperua falcata), some species shared a very similar slope (e.g., Qualea rosea vs. Vouacapoua americana). It might therefore be possible to use a common model between these species

Object-based prediction was better correlated to basal area than pixel-based prediction (4-8 point gain in $\mathrm{R}^{2}$ ) for all classifiers. Less than $2 \%$ of the pixels were classified into more than one species for both LDA and RDA. Hence, the confusion was low, despite the fact that the species-specific classifiers were developed independently. After majority voting, no confusion remained.

\section{Discussion}

The first experiment unambiguously confirmed that addition of SWIR information vastly improves classification performance. Our results on the contribution of SWIR information to species identification are in line with those obtained in previous studies [23,26,44]. The authors of [23] found that the LDA classification accuracy of seven tropical forest tree species was improved from $67.3 \%$ to $83.6 \%$. Similarly, we found an increase in accuracy of about $20 \%-25 \%$ on average across species depending on the method considered. We noted that the gain was more important for LDA and RDA than for LR. In addition, we assessed the quality of our database. In fact, our database may contain a few mislabeled cases, as suggested by the Mahalanobis distance analysis. However, these outliers had a limited negative effect on classification in general. It is unclear how many of these pseudo-outliers are actual outliers. Phenology or presence of lianas was not found to be significantly associated with potential outliers.

The comparison of the results obtained in this study (Table 3, without bias) with previously published results (Table 4 in Laybros et al., 2019) indicates that there is no significant difference in performance between the binary and multiclass LDA classifier at pixel level. However, at the object level, the binary classifiers are clearly outperformed, implying a strong influence of the majority vote. The relative majority can be effective in a multi-class problem, whereas the absolute majority is required when only two classes are considered.

An important characteristic of our study case is the unbalanced number of spectra (pixels) in each class. The minority classes are the most affected by this constraint. Unbalanced classes impact results obtained with SVM classifications [45]. In some studies, the authors used SVM without a specific method to control for this effect $[20,21,24,26,46]$. This method is, however, sensitive to unbalanced classes [47-50]. Biasing the classifier by adding weights and breaking down the penalization of the classifiers (parameter C) into two parameters was recommended by $[19,51]$ in order to reduce the negative impact of the minority classes. Conversely, LDA is not sensitive to the number of elements per class [52] because it shares the variance-covariation matrix between the classes. In addition, training on the entire data set or a subset of only 30 crowns did not affect the performance of the classifier. The similar results between the LDA and the RDA methods seem to confirm that RDA IS not sensitive to the disproportion between classes either.

It is preferable to optimize a specific metric in the biased cases and especially with a high bias rate. F-measure is not a good choice, because the precision is biased to an unknown extent. The use of the criterion proposed by [29] proved useful. In addition, when the bias is very severe, it is recommended to use a threshold that will optimize discrimination [49]. In the present study, LR was found to benefit much from this methodology. Conversely, the optimal probability threshold did not improve species discrimination for RDA.

The maximum level of bias tested here was $5 \%$. How likely are larger biases to occur? In an operational case, the random selection of pixels on the study area will comprise a range of species 
reflecting the local flora of the study site. Despite the extremely high local tree species diversity (alpha diversity) in tropical forests [53], some species are spatially aggregated as a result of either environmental preference or dispersal limitation. For example, the Eperua falcata measured in the Piste de St Ellie region, is a species with an aggregated spatial distribution [54]. Vouacapoua americana, Eperua grandiflora and Qualea rosea species were also reported as being highly aggregated $[55,56]$. Extreme cases of aggregation may lead to monodominance [57], where more than $50 \%$ of the stems belong to a single species (e.g., Spirotropis longifolia). This, however, is a rare case and local frequency of the focal species will seldom reach $5 \%$ [58].

Most previous studies focused on discriminating a few well-known species against each other, which is of little relevance to an operational context. Here, we focused on assessing the potential of classification methods using hyperspectral information for retrieving particular species in a diverse canopy. This problem was previously addressed by [19], who highlighted the feasibility of identifying four tree species in a tropical forest canopy using biased SVM on the BCI site. As reported by [59], the taxonomic diversity in $\mathrm{BCI}$ is lower than in Paracou, whatever the diversity considered (alpha, beta or gamma diversity). On the BCI site, 225 tree species have been counted among more than 21,457 stems for an area of 50 hectares. On the Paracou site, 229 tree species were listed among 1124 stems for an area of 2 hectares. Therefore, the identification of focal tree species may be more challenging in the context of the present study than in the [19] study. As shown in Experiment 1, the performance of the classifiers tends to decrease with increasing diversity of the background.

The size of the training data set can be critical in an operational setting. The minimum number of crowns to be used for training in tropical canopies was investigated by $[18,45]$. Thirty crowns were found to be reasonable for species retrieval against 100,000 pixels. In the present study reducing the number of focal crowns from 74-144 to 30 crowns did not entail any loss in F-measure (comparison between Table 3 and Figure A1). However, the minimum training set size may depend on the species [18] and the diversity of the canopy. For the same number of crowns in the learning set (34 crowns, Table 1), the F-measure for Vouacapoua americana reached of $72.8 \%$ while it was only $36.7 \%$ for Symphonia sp.1 (Table 3, RDA). In addition, because classification results were so variable across species (Figure 4), we examined correlations between the predictability of the species (F-measure), the size of the focal species training set, the intra-specific spectral variance-sensu [60] —and the dispersion of the Mahalanobis distance values. The only significant correlation detected was with the size of the training set (number of crowns or number pixels) highlighting that the detectability of a species is difficult to predict (Appendix F, Table A5).

Forest managers need to quantify the resource of the forest in order to orient the choices to be made. We found the relation between basal area and crown area in the canopy to vary across species. The authors of [61] mention that a global allometric model can predict the diameter of the crown from the diameter of the stem. These estimates are based on more than 108,753 stems with different geographic locations, consisting of 1,492 tree species. However, this general relation is only valid at coarse grain, and studies comparing species occurring in a restricted geographical range repeatedly found marked inter-species differences. This was the case for Indian monsoon forest [62] and Sumatran peneplains agroforests [63], for instance. In addition, it should be stressed that, albeit visible from above (and therefore segmented and labeled), a crown may be partially masked by its neighbors, so the area of the visible segment can differ from the total crown area. Finally, errors stemming from the automatic segmentation step may have further blurred the basal area-crown area relation.

The use of LiDAR data allowed us to cluster points into putative crowns using the AMS-3D algorithm. This segmentation step allowed improving the performance of classifications through majority voting by an average of $10 \%-18 \%$. This suggests that improving the segmentation step might provide improvement in the classification results. Segmentation itself may take advantage of multisource data. Depending of the way data are merged, fine co-registration can be required but may be difficult to achieve $[64,65]$. 
The next major challenge to address in remote species classification is transferring the knowledge acquired on one site to another one [22]. The spectral signature may vary over both space and time. One reason is variation in the timing of leafing, fruiting and flowering, which is still not well characterized for the vast majority of species in evergreen forest [66]. Tropical rainforest trees produce leaves with widely variable phenology and longevity $[67,68]$. Leaf optical properties may differ significantly between young newly sprouted leaves and one- to two-month-old fully mature photo-synthetically competent leaves [69]. In French Guiana where our study took place, a seminal work [70] monitored the phenology of 750 trees belonging to 35 species during two years. Various leafing patterns were reported to occur in that study: deciduous with synchronous or asynchronous leaf drop, or evergreen with continuous or seasonal leaf flushing. Local conditions (and notably soil water holding capacity) will contribute to desynchronize the phenological stage of deciduous trees submitted to similar weather conditions. Difference in tree water status may also alter leaf inclination through wilting which may affect the crown reflectance properties [71]. Additionally, differences in soil chemical fertility may induce differences in the spectral signatures of species. A long-known effect of an increase in nitrogen availability is an increased chlorophyll content and greenness [72]. The second major reason, and probably the most stringent issue, is the variability in imaging conditions. Several factors come into play to modify the apparent reflectance. On the one hand, during the acquisition, the sun-sensor angles change, as both the positions of the sun and the sensor are changing. The reflectance depends on those angles, and this dependency is idiosyncratic (i.e., depends on the characteristics of the object being imaged). Modelling the bidirectional reflectance distribution function (BDRF) to correct these spurious variations in spectral signature is extremely delicate. BRDF is likely to vary from tree to tree as it depends on characteristics such as foliage density, crown geometry (leaf size, leaf angle). Empirical or semi-empirical kernel-driven models [73] would probably require very large datasets to achieve a reasonable level of accuracy. The fact that reflectance in NIR is also significantly affected by neighbors identity [69] renders the hyper-diverse tropical forest particularly challenging in this respect.

\section{Conclusions}

We present a method that leverages the fusion of LiDAR data for ITC mapping and hyperspectral imagery for species identification. This method allowed us to accurately predict basal area of commercial species in a highly diverse tropical forest. As both types of sensors are likely to become more and more common, we hope that the proposed method will promote sustainable management of tropical forest.

Addition of the SWIR domain (1000nm to 2500nm) to the more commonly used VNIR spectrum was very useful and is strongly recommended whenever possible. In this study, we have examined different scenarios that forest managers may encounter to map specific species in tropical forests, including limited training set and labeling errors affecting both the focal and non-focal classes. We have successfully tested various methods to circumvent labeling error issues. We recommend using robust discriminant analysis, which seems to be the method least sensitive to bias while also offering very good results in the absence of bias in the training data. In addition, we have found that sampling can be limited to a few individuals ( 30 crowns) without reducing the accuracy of the classifications. Certain species were poorly identified with all classification methods. No indicator based on spectral characteristics allowed upstream identification of what made it possible to carry out an efficient classification of a given tree species.

Author Contributions: Conceptualization, A.L. and G.V.; methodology, A.L. and G.V.; validation, A.L.; formal analysis, A.L. and G.V.; investigation, A.L.; resources, G.V. and J.-B.F.; data curation, A.L.; writing-original draft preparation, A.L.; writing - review and editing, A.L., M.A.-K., J-B.F., C.B., O.B., G.D. and G.V.; visualization, A.L., G.V. and M.A.-K.; supervision, G.V.; project administration, C.B. and O.B.; All authors have read and agreed to the published version of the manuscript.

Funding: This work is part of the CartoDivDendroLidar project funded by the Fond stratégique de la forêt et du bois (FSFB) of the French Ministry of Agriculture (FSFB) and the Investissement d'Avenir grants from the Agence Nationale de la Recherche (CEBA, ref ANR-10-LABX-25-01 - CeMEB ANR-10-LABX-04-01). 
Acknowledgments: A. Laybros acknowledges financial support from the French Ministry of Higher Education, Research and Innovation (MESRI) through CIFRE contract $n^{\circ}$ 2017/0405. Field support from Jean-Louis Smock (AMAP-IRD), Chantal Geniez (AMAP-IRD), Carla Baltzer (AMAP-IRD) and Raphaël Dutrieux (AMAP-IRD) is gratefully acknowledged. Hyperspectral imagery acquisition was funded by the CNES (Centre National des Etudes Spatiales). J.-B. Féret acknowledges financial support from Agence Nationale de la Recherche (BioCop project-ANR-17-CE32-0001) and TOSCA program grant of the French Space Agency (CNES) (HyperTropik/HyperBIO project).

Conflicts of Interest: The authors declare no conflict of interest.

\section{Appendix A. Experiment 1}

Table A1. Pixel-level results from the one versus 19 other species method. Only the F-measure is given with the standard deviation. The best prediction for each species with either VNIR or VSWIR information is in bold.

\begin{tabular}{|c|c|c|c|c|c|c|}
\hline \multirow{2}{*}{ Species } & \multicolumn{3}{|c|}{ VNIR } & \multicolumn{3}{|c|}{ VSWIR } \\
\hline & LDA & RDA & LR & LDA & RDA & LR \\
\hline B.p. & $13.2( \pm 6.5)$ & $18.2( \pm 10.4)$ & $24.1( \pm 12.8)$ & $42.7( \pm 7.7)$ & $65.2( \pm 6.5)$ & $54.7( \pm 7.8)$ \\
\hline C.m. & $66.8( \pm 12.0)$ & $65.0( \pm 12.6)$ & $67.2( \pm 10.5)$ & $75.3( \pm 8.0)$ & $72.2( \pm 8.5)$ & $75.6( \pm 5.9)$ \\
\hline D.g. & $54.2( \pm 4.3)$ & $51.9( \pm 5.8)$ & $60.1( \pm 4.8)$ & $76.1( \pm 3.3)$ & $75.0( \pm 3.6)$ & $78.9( \pm 3.0)$ \\
\hline$\overline{\text { E.f. }}$ & $33.6( \pm 4.5)$ & $14.1( \pm 3.2)$ & $36.5( \pm 4.5)$ & $59.3( \pm 5.2)$ & $66.6( \pm 6.2)$ & $69.4( \pm 4.8)$ \\
\hline$\overline{E . g .}$ & $49.2( \pm 6.5)$ & $56.3( \pm 4.9)$ & $69.6( \pm 4.2)$ & $74.6( \pm 3.5)$ & $79.9( \pm 3.4)$ & $81.5( \pm 2.7)$ \\
\hline$\overline{E . s .}$ & $59.3( \pm 3.4)$ & $66.2( \pm 3.9)$ & $65.7( \pm 4.2)$ & $75.8( \pm 3.0)$ & $78.2( \pm 3.0)$ & $75.6( \pm 3.4)$ \\
\hline$\overline{G . g}$. & $37.8( \pm 9.7)$ & $62.2( \pm 9.1)$ & $67.4( \pm 9.3)$ & $80.6( \pm 6.2)$ & $81.3( \pm 8.2)$ & $77.2( \pm 10.2)$ \\
\hline I. $a$. & $38.1( \pm 11.0)$ & $45.9( \pm 13.9)$ & $64.6( \pm 12.0)$ & $63.6( \pm 9.5)$ & $69.2( \pm 7.5)$ & $64.6( \pm 8.1)$ \\
\hline J.c. & $58.8( \pm 19.4)$ & $59.5( \pm 22.7)$ & $54.5( \pm 20.4)$ & $56.8( \pm 16.9)$ & $53.4( \pm 20.5)$ & $55.3( \pm 12.5)$ \\
\hline L.a. & $34.0( \pm 7.3)$ & $52.1( \pm 9.4)$ & $54.0( \pm 9.7)$ & $58.0( \pm 7.9)$ & $67.4( \pm 8.7)$ & $64.2( \pm 6.0)$ \\
\hline L.h. & $9.4( \pm 3.9)$ & $5.6( \pm 4.8)$ & $5.6( \pm 4.8)$ & $20.3( \pm 8.3)$ & $46.5( \pm 12.3)$ & $36.0( \pm 9.4)$ \\
\hline M.c. & $45.5( \pm 9.3)$ & $50.0( \pm 11.3)$ & $64.4( \pm 9.1)$ & $68.8( \pm 9.0)$ & $70.0( \pm 11.1)$ & $71.1( \pm 5.9)$ \\
\hline P.c. & $78.2( \pm 3.2)$ & $78.8( \pm 1.5)$ & $81.3( \pm 1.6)$ & $89.1( \pm 1.6)$ & $88.2( \pm 1.4)$ & $88.9( \pm 1.6)$ \\
\hline Q.r. & $88.4( \pm 2.0)$ & $88.1( \pm 1.6)$ & $90.8( \pm 0.8)$ & $94.0( \pm 0.8)$ & $93.0( \pm 1.0)$ & $94.4( \pm 0.8)$ \\
\hline$\overline{R . s .}$ & $76.6( \pm 5.0)$ & $75.1( \pm 5.3)$ & $81.3( \pm 3.4)$ & $84.1( \pm 3.5)$ & $82.4( \pm 4.4)$ & $81.7( \pm 3.5)$ \\
\hline S.r. & $36.4( \pm 7.8)$ & $52.3( \pm 10.3)$ & $55.3( \pm 10.0)$ & $53.8( \pm 10.4)$ & $69.2( \pm 6.6)$ & $71.7( \pm 4.6)$ \\
\hline S.s. & $13.2( \pm 3.8)$ & $0.4( \pm 0.4)$ & $10.4( \pm 2.7)$ & $33.9( \pm 8.4)$ & $54.6( \pm 6.1)$ & $52.4( \pm 6.6)$ \\
\hline T.m. & $63.3( \pm 7.8)$ & $67.8( \pm 7.6)$ & $68.5( \pm 5.8)$ & $87.7( \pm 3.4)$ & $87.1( \pm 3.5)$ & $85.5( \pm 3.4)$ \\
\hline T.c. & $7.4( \pm 2.7)$ & $8.8( \pm 6.3)$ & $40.5( \pm 9.0)$ & $30.3( \pm 7.6)$ & $60.0( \pm 12.1)$ & $59.2( \pm 8.7)$ \\
\hline V.a. & $31.2( \pm 8.6)$ & $48.6( \pm 10.0)$ & $46.3( \pm 12.5)$ & $69.6( \pm 5.8)$ & $72.4( \pm 7.8)$ & $63.0( \pm 7.1)$ \\
\hline Mean $\overline{\text { F-measue }}$ & 44.7 & 48.3 & 55.4 & 64.7 & 71.6 & 70.1 \\
\hline
\end{tabular}

LDA's performance is the lowest compared to RDA and LR, both with (64.7\% vs. $71.6 \%)$ and without (44.7\% vs. $48.3 \%$ ) an SWIR spectrum. At object level, LDA and RDA were the best methods. 


\section{Appendix B. Experiment 3 (Low Level of Impurity)—Complement}

Table A2. Full table for the comparison between methods and bias applied, with and without optimisation step. Plain and optimized indicate whether an optimization step (selecting a threshold probability value) was applied to maximize either the F measure ( $0 \%$ contamination) or the Lee and Liu 2003 criterion ( $1 \%$ contamination). The F-measure is given at crown scale. The best prediction for each species, configurations and methods is in bold.

\begin{tabular}{|c|c|c|c|c|c|c|c|c|c|c|c|c|c|c|c|c|c|c|c|c|c|c|c|c|}
\hline \multirow{3}{*}{$\begin{array}{c}\text { Bias } \\
\text { Species }\end{array}$} & \multicolumn{6}{|c|}{$0 \%$} & \multicolumn{6}{|c|}{$1 \%$} & \multicolumn{6}{|c|}{$2 \%$} & \multicolumn{6}{|c|}{$5 \%$} \\
\hline & \multicolumn{3}{|c|}{ Plain } & \multicolumn{3}{|c|}{ Optimized } & \multicolumn{3}{|c|}{ Plain } & \multicolumn{3}{|c|}{ Optimized } & \multicolumn{3}{|c|}{ Plain } & \multicolumn{3}{|c|}{ Optimized } & \multicolumn{3}{|c|}{ Plain } & \multicolumn{3}{|c|}{ Optimized } \\
\hline & LDA & RDA & LR & LDA & RDA & LR & LDA & RDA & LR & LDA & RDA & LR & LDA & RDA & LR & LDA & RDA & LR & LDA & RDA & LR & LDA & RDA & LR \\
\hline B.p. & $\begin{array}{c}35.8 \\
( \pm 10.3)\end{array}$ & $\begin{array}{c}57.7 \\
( \pm 12.4)\end{array}$ & $\begin{array}{c}37.5 \\
( \pm 15.5)\end{array}$ & $\begin{array}{c}65.4 \\
( \pm 12.6)\end{array}$ & $\begin{array}{c}57.5 \\
( \pm 17.4)\end{array}$ & $\begin{array}{c}42.1 \\
( \pm 16.0)\end{array}$ & $\begin{array}{c}36.4 \\
( \pm 9.8)\end{array}$ & $\begin{array}{c}58.5 \\
( \pm 12.4)\end{array}$ & $\begin{array}{c}43.4 \\
( \pm 13.6)\end{array}$ & $\begin{array}{c}64.3 \\
( \pm 12.7)\end{array}$ & $\begin{array}{c}56.2 \\
( \pm 17.3)\end{array}$ & $\begin{array}{c}43.0 \\
( \pm 16.0)\end{array}$ & - & - & - & - & - & - & - & - & - & - & - & - \\
\hline C.m. & $\begin{array}{c}68.3 \\
( \pm 10.8)\end{array}$ & $\begin{array}{c}64.7 \\
( \pm 10.1)\end{array}$ & $\begin{array}{c}68.0 \\
( \pm 10.5)\end{array}$ & $\begin{array}{c}69.8 \\
( \pm 11.2)\end{array}$ & $\begin{array}{c}68.3 \\
( \pm 11.3)\end{array}$ & $\begin{array}{c}71.4 \\
( \pm 7.9)\end{array}$ & $\begin{array}{l}67.4 \\
( \pm 11.2)\end{array}$ & $\begin{array}{c}65.1 \\
( \pm 10.3)\end{array}$ & $\begin{array}{c}66.5 \\
( \pm 9.5)\end{array}$ & $\begin{array}{c}69.8 \\
( \pm 11.6)\end{array}$ & $\begin{array}{c}68.0 \\
( \pm 11.3)\end{array}$ & $\begin{array}{c}69.4 \\
( \pm 8.4)\end{array}$ & - & - & - & - & - & - & - & - & - & - & - & - \\
\hline D.g. & $\begin{array}{c}57.7 \\
( \pm 3.9)\end{array}$ & $\begin{array}{c}72.3 \\
( \pm 6.0)\end{array}$ & $\begin{array}{c}78.2 \\
( \pm 6.1)\end{array}$ & $\begin{array}{c}75.8 \\
( \pm 5.6)\end{array}$ & $\begin{array}{c}72.0 \\
( \pm 6.3)\end{array}$ & $\begin{array}{c}78.5 \\
( \pm 5.7)\end{array}$ & $\begin{array}{l}57.5 \\
( \pm 3.8)\end{array}$ & $\begin{array}{r}72.6 \\
( \pm 5.7)\end{array}$ & $\begin{array}{c}78.2 \\
( \pm 5.5)\end{array}$ & $\begin{array}{c}74.8 \\
( \pm 6.3)\end{array}$ & $\begin{array}{c}72.2 \\
( \pm 5.4)\end{array}$ & $\begin{array}{c}78.3 \\
( \pm 5.5)\end{array}$ & $\begin{array}{c}56.2 \\
( \pm 4.2)\end{array}$ & $\begin{array}{c}69.6 \\
( \pm 4.7)\end{array}$ & $\begin{array}{c}76.5 \\
( \pm 5.7)\end{array}$ & $\begin{array}{c}72.5 \\
( \pm 5.2)\end{array}$ & $\begin{array}{c}67.2 \\
( \pm 4.9)\end{array}$ & $\begin{array}{c}73.2 \\
( \pm 5.0)\end{array}$ & $\begin{array}{c}58.5 \\
( \pm 4.4)\end{array}$ & $\begin{array}{c}70.3 \\
( \pm 4.6)\end{array}$ & $\begin{array}{c}72.3 \\
( \pm 4.8)\end{array}$ & $\begin{array}{c}73.1 \\
( \pm 5.0)\end{array}$ & $\begin{array}{c}68.0 \\
( \pm 4.9)\end{array}$ & $\begin{array}{r}73.1 \\
( \pm 4.4)\end{array}$ \\
\hline E.f. & $\begin{array}{l}50.8 \\
( \pm 4.1)\end{array}$ & $\begin{array}{c}67.7 \\
( \pm 6.1)\end{array}$ & $\begin{array}{c}69.2 \\
( \pm 6.2)\end{array}$ & $\begin{array}{c}71.5 \\
( \pm 4.6)\end{array}$ & $\begin{array}{c}68.9 \\
( \pm 5.2)\end{array}$ & $\begin{array}{c}70.5 \\
( \pm 5.0)\end{array}$ & $\begin{array}{l}51.5 \\
( \pm 4.2)\end{array}$ & $\begin{array}{c}67.9 \\
( \pm 5.2)\end{array}$ & $\begin{array}{c}68.0 \\
( \pm 5.4)\end{array}$ & $\begin{array}{c}72.1 \\
( \pm 4.8)\end{array}$ & $\begin{array}{c}69.2 \\
( \pm 4.5)\end{array}$ & $\begin{array}{c}70.5 \\
( \pm 4.9)\end{array}$ & $\begin{array}{c}51.4 \\
( \pm 4.1)\end{array}$ & $\begin{array}{c}62.5 \\
( \pm 6.1)\end{array}$ & $\begin{array}{l}61.9 \\
( \pm 6.5)\end{array}$ & $\begin{array}{c}67.3 \\
( \pm 6.0)\end{array}$ & $\begin{array}{l}63.4 \\
( \pm 5.9)\end{array}$ & $\begin{array}{c}65.0 \\
( \pm 5.5)\end{array}$ & $\begin{array}{c}52.8 \\
( \pm 5.4)\end{array}$ & $\begin{array}{c}62.0 \\
( \pm 5.7)\end{array}$ & $\begin{array}{c}50.7 \\
( \pm 8.5)\end{array}$ & $\begin{array}{c}66.0 \\
( \pm 5.4)\end{array}$ & $\begin{array}{l}62.2 \\
( \pm 6.6)\end{array}$ & $\begin{array}{c}59.3 \\
( \pm 7.0)\end{array}$ \\
\hline E.g. & $\begin{array}{c}65.1 \\
( \pm 7.0)\end{array}$ & $\begin{array}{c}82.0 \\
( \pm 5.3)\end{array}$ & $\begin{array}{c}84.4 \\
( \pm 4.6)\end{array}$ & $\begin{array}{c}82.4 \\
( \pm 6.2)\end{array}$ & $\begin{array}{c}82.7 \\
( \pm 6.2)\end{array}$ & $\begin{array}{c}84.8 \\
( \pm 4.5)\end{array}$ & $\begin{array}{c}64.9 \\
( \pm 6.9)\end{array}$ & $\begin{array}{c}81.9 \\
( \pm 5.6)\end{array}$ & $\begin{array}{c}82.5 \\
( \pm 6.0)\end{array}$ & $\begin{array}{c}82.0 \\
( \pm 6.2)\end{array}$ & $\begin{array}{c}82.5 \\
( \pm 6.0)\end{array}$ & $\begin{array}{c}84.7 \\
( \pm 4.2)\end{array}$ & - & - & - & - & - & - & - & - & - & - & - & - \\
\hline E.S. & $\begin{array}{c}68.1 \\
( \pm 4.2)\end{array}$ & $\begin{array}{c}74.2 \\
( \pm 4.1)\end{array}$ & $\begin{array}{c}71.0 \\
( \pm 5.2)\end{array}$ & $\begin{array}{c}74.7 \\
( \pm 4.3)\end{array}$ & $\begin{array}{c}74.1 \\
( \pm 4.6)\end{array}$ & $\begin{array}{c}75.9 \\
( \pm 4.7)\end{array}$ & $\begin{array}{c}68.5 \\
( \pm 4.5)\end{array}$ & $\begin{array}{c}74.7 \\
( \pm 3.9)\end{array}$ & $\begin{array}{c}69.2 \\
( \pm 6.0)\end{array}$ & $\begin{array}{c}74.1 \\
( \pm 4.3)\end{array}$ & $\begin{array}{c}73.4 \\
( \pm 4.1)\end{array}$ & $\begin{array}{c}74.9 \\
( \pm 5.0)\end{array}$ & $\begin{array}{c}67.4 \\
( \pm 5.0)\end{array}$ & $\begin{array}{c}74.1 \\
( \pm 4.3)\end{array}$ & $\begin{array}{c}69.0 \\
( \pm 6.2)\end{array}$ & $\begin{array}{c}74.2 \\
( \pm 4.4)\end{array}$ & $\begin{array}{c}74.2 \\
( \pm 4.0)\end{array}$ & $\begin{array}{c}73.3 \\
( \pm 4.6)\end{array}$ & $\begin{array}{c}69.8 \\
( \pm 5.5)\end{array}$ & $\begin{array}{c}72.8 \\
( \pm 4.4)\end{array}$ & $\begin{array}{c}47.1 \\
( \pm 8.7)\end{array}$ & $\begin{array}{c}72.0 \\
( \pm 4.5)\end{array}$ & $\begin{array}{c}72.0 \\
( \pm 4.0)\end{array}$ & $\begin{array}{c}61.7 \\
( \pm 7.6)\end{array}$ \\
\hline G.g. & $\begin{array}{c}62.5 \\
( \pm 12.6)\end{array}$ & $\begin{array}{c}73.4 \\
( \pm 11.5)\end{array}$ & $\begin{array}{c}76.4 \\
( \pm 12.5)\end{array}$ & $\begin{array}{c}74.5 \\
( \pm 10.1)\end{array}$ & $\begin{array}{c}73.5 \\
( \pm 10.9)\end{array}$ & $\begin{array}{c}77.3 \\
( \pm 12.3)\end{array}$ & $\begin{array}{c}62.8 \\
( \pm 14.2)\end{array}$ & $\begin{array}{c}72.6 \\
( \pm 10.5)\end{array}$ & $\begin{array}{c}74.8 \\
( \pm 11.6)\end{array}$ & $\begin{array}{c}74.5 \\
( \pm 10.6)\end{array}$ & $\begin{array}{c}74.4 \\
( \pm 11.2)\end{array}$ & $\begin{array}{c}75.0 \\
( \pm 12.9)\end{array}$ & - & - & - & - & - & - & - & - & - & - & - & - \\
\hline I.a. & $\begin{array}{c}38.3 \\
( \pm 11.5)\end{array}$ & $\begin{array}{c}42.3 \\
( \pm 12.7)\end{array}$ & $\begin{array}{c}38.5 \\
( \pm 11.6)\end{array}$ & $\begin{array}{c}43.0 \\
( \pm 12.9)\end{array}$ & $\begin{array}{l}41.0 \\
( \pm 13.3)\end{array}$ & $\begin{array}{c}41.4 \\
( \pm 13.1)\end{array}$ & $\begin{array}{c}38.9 \\
( \pm 11.2)\end{array}$ & $\begin{array}{c}42.7 \\
( \pm 12.5)\end{array}$ & $\begin{array}{c}36.6 \\
( \pm 10.7)\end{array}$ & $\begin{array}{c}43.0 \\
( \pm 14.4)\end{array}$ & $\begin{array}{c}41.4 \\
( \pm 13.5)\end{array}$ & $\begin{array}{c}40.9 \\
( \pm 14.2)\end{array}$ & - & - & - & - & - & - & - & - & - & - & - & - \\
\hline J.c. & $\begin{array}{l}50.7 \\
( \pm 19.7)\end{array}$ & $\begin{array}{c}51.4 \\
( \pm 16.8)\end{array}$ & $\begin{array}{c}\mathbf{5 2 . 4} \\
( \pm 17.1)\end{array}$ & $\begin{array}{c}50.9 \\
( \pm 16.9)\end{array}$ & $\begin{array}{c}49.3 \\
( \pm 17.5)\end{array}$ & $\begin{array}{c}53.1 \\
( \pm 17.2)\end{array}$ & $\begin{array}{c}52.2 \\
( \pm 17.2)\end{array}$ & $\begin{array}{c}49.0 \\
( \pm 16.9)\end{array}$ & $\begin{array}{c}51.6 \\
( \pm 16.6)\end{array}$ & $\begin{array}{c}51.5 \\
( \pm 17.6)\end{array}$ & $\begin{array}{c}50.4 \\
( \pm 16.5)\end{array}$ & $\begin{array}{c}\mathbf{5 2 . 6} \\
( \pm 18.7)\end{array}$ & - & - & - & - & - & - & - & - & - & - & - & - \\
\hline L.a. & $\begin{array}{l}41.6 \\
( \pm 8.7)\end{array}$ & $\begin{array}{c}56.3 \\
( \pm 10.8)\end{array}$ & $\begin{array}{c}53.9 \\
( \pm 10.5)\end{array}$ & $\begin{array}{c}56.6 \\
( \pm 11.1)\end{array}$ & $\begin{array}{l}54.4 \\
( \pm 10.6)\end{array}$ & $\begin{array}{c}62.3 \\
( \pm 10.3)\end{array}$ & $\begin{array}{c}41.9 \\
( \pm 9.9)\end{array}$ & $\begin{array}{c}56.8 \\
( \pm 10.2)\end{array}$ & $\begin{array}{c}48.5 \\
( \pm 12.1)\end{array}$ & $\begin{array}{c}57.0 \\
( \pm 10.5)\end{array}$ & $\begin{array}{c}54.7 \\
( \pm 10.1)\end{array}$ & $\begin{array}{c}59.7 \\
( \pm 8.8)\end{array}$ & - & - & - & - & - & - & - & - & - & - & - & - \\
\hline L.h. & $\begin{array}{l}25.6 \\
( \pm 8.9)\end{array}$ & $\begin{array}{c}43.6 \\
( \pm 11.0)\end{array}$ & $\begin{array}{l}22.8 \\
( \pm 8.1)\end{array}$ & $\begin{array}{c}44.0 \\
( \pm 12.3)\end{array}$ & $\begin{array}{c}34.2 \\
( \pm 13.1)\end{array}$ & $\begin{array}{l}25.5 \\
( \pm 7.6)\end{array}$ & $\begin{array}{c}26.5 \\
( \pm 8.9)\end{array}$ & $\begin{array}{c}43.5 \\
( \pm 13.6)\end{array}$ & $\begin{array}{c}23.5 \\
( \pm 8.3)\end{array}$ & $\begin{array}{c}46.6 \\
( \pm 9.4)\end{array}$ & $\begin{array}{c}33.7 \\
( \pm 11.5)\end{array}$ & $\begin{array}{c}26.0 \\
( \pm 10.6)\end{array}$ & - & - & - & - & - & - & - & - & - & - & - & - \\
\hline M.c. & $\begin{array}{c}58.5 \\
( \pm 13.8)\end{array}$ & $\begin{array}{c}55.5 \\
( \pm 16.9)\end{array}$ & $\begin{array}{c}60.0 \\
( \pm 14.5)\end{array}$ & $\begin{array}{c}56.3 \\
( \pm 15.9)\end{array}$ & $\begin{array}{c}54.9 \\
( \pm 16.0)\end{array}$ & $\begin{array}{c}62.7 \\
( \pm 12.0)\end{array}$ & $\begin{array}{c}58.6 \\
( \pm 12.8)\end{array}$ & $\begin{array}{c}56.1 \\
( \pm 16.5)\end{array}$ & $\begin{array}{c}56.5 \\
( \pm 16.9)\end{array}$ & $\begin{array}{c}55.4 \\
( \pm 16.5)\end{array}$ & $\begin{array}{c}56.2 \\
( \pm 15.6)\end{array}$ & $\begin{array}{c}61.7 \\
( \pm 14.8)\end{array}$ & - & - & - & - & - & - & - & - & - & - & - & - \\
\hline P.c. & $\begin{array}{c}69.5 \\
( \pm 4.5)\end{array}$ & $\begin{array}{c}77.1 \\
( \pm 4.9)\end{array}$ & $\begin{array}{c}85.9 \\
( \pm 3.6)\end{array}$ & $\begin{array}{c}77.6 \\
( \pm 4.5)\end{array}$ & $\begin{array}{c}77.0 \\
( \pm 4.6)\end{array}$ & $\begin{array}{c}84.3 \\
( \pm 3.2)\end{array}$ & $\begin{array}{c}69.6 \\
( \pm 4.9)\end{array}$ & $\begin{array}{c}78.0 \\
( \pm 4.9)\end{array}$ & $\begin{array}{c}85.8 \\
( \pm 3.2)\end{array}$ & $\begin{array}{r}78.2 \\
( \pm 4.7)\end{array}$ & $\begin{array}{c}77.4 \\
( \pm 4.8)\end{array}$ & $\begin{array}{c}84.0 \\
( \pm 3.8)\end{array}$ & $\begin{array}{c}70.4 \\
( \pm 4.9)\end{array}$ & $\begin{array}{c}80.4 \\
( \pm 3.4)\end{array}$ & $\begin{array}{c}84.6 \\
( \pm 4.6)\end{array}$ & $\begin{array}{c}79.9 \\
( \pm 3.6)\end{array}$ & $\begin{array}{c}79.8 \\
( \pm 3.5)\end{array}$ & $\begin{array}{c}84.2 \\
( \pm 3.4)\end{array}$ & $\begin{array}{c}71.4 \\
( \pm 4.8)\end{array}$ & $\begin{array}{c}79.3 \\
( \pm 3.8)\end{array}$ & $\begin{array}{c}74.2 \\
( \pm 7.7)\end{array}$ & $\begin{array}{c}79.3 \\
( \pm 3.8)\end{array}$ & $\begin{array}{c}78.7 \\
( \pm 3.5)\end{array}$ & $\begin{array}{r}81.9 \\
( \pm 4.5)\end{array}$ \\
\hline Q.r. & $\begin{array}{c}86.6 \\
( \pm 2.5)\end{array}$ & $\begin{array}{r}88.1 \\
( \pm 2.7)\end{array}$ & $\begin{array}{c}91.3 \\
( \pm 2.3)\end{array}$ & $\begin{array}{c}86.4 \\
( \pm 2.6)\end{array}$ & $\begin{array}{l}85.8 \\
( \pm 2.4)\end{array}$ & $\begin{array}{c}90.7 \\
( \pm 2.6)\end{array}$ & $\begin{array}{c}86.9 \\
( \pm 2.5)\end{array}$ & $\begin{array}{l}88.1 \\
( \pm 2.5)\end{array}$ & $\begin{array}{c}91.2 \\
( \pm 2.2)\end{array}$ & $\begin{array}{c}86.6 \\
( \pm 2.6)\end{array}$ & $\begin{array}{c}86.2 \\
( \pm 2.8)\end{array}$ & $\begin{array}{c}90.8 \\
( \pm 2.4)\end{array}$ & $\begin{array}{c}88.0 \\
( \pm 2.5)\end{array}$ & $\begin{array}{c}89.0 \\
( \pm 2.5)\end{array}$ & $\begin{array}{c}92.2 \\
( \pm 2.0)\end{array}$ & $\begin{array}{c}85.6 \\
( \pm 3.1)\end{array}$ & $\begin{array}{c}85.7 \\
( \pm 2.7)\end{array}$ & $\begin{array}{c}90.6 \\
( \pm 1.8)\end{array}$ & $\begin{array}{c}87.9 \\
( \pm 2.6)\end{array}$ & $\begin{array}{c}89.4 \\
( \pm 2.7)\end{array}$ & $\begin{array}{c}92.1 \\
( \pm 2.4)\end{array}$ & $\begin{array}{c}86.6 \\
( \pm 3.2)\end{array}$ & $\begin{array}{c}86.4 \\
( \pm 3.0)\end{array}$ & $\begin{array}{c}90.4 \\
( \pm 2.6)\end{array}$ \\
\hline R.s. & $\begin{array}{c}82.5 \\
( \pm 3.8)\end{array}$ & $\begin{array}{c}78.8 \\
( \pm 4.5)\end{array}$ & $\begin{array}{r}81.2 \\
( \pm 5.2)\end{array}$ & $\begin{array}{l}81.0 \\
( \pm 3.7)\end{array}$ & $\begin{array}{c}80.7 \\
( \pm 3.5)\end{array}$ & $\begin{array}{r}84.9 \\
( \pm 4.5)\end{array}$ & $\begin{array}{c}82.4 \\
( \pm 4.2)\end{array}$ & $\begin{array}{l}79.3 \\
( \pm 5.0)\end{array}$ & $\begin{array}{l}79.5 \\
( \pm 5.6)\end{array}$ & $\begin{array}{c}80.7 \\
( \pm 4.4)\end{array}$ & $\begin{array}{l}79.7 \\
( \pm 4.1)\end{array}$ & $\begin{array}{c}83.4 \\
( \pm 5.3)\end{array}$ & - & - & - & - & - & - & - & - & - & - & - & - \\
\hline S.r. & $\begin{array}{c}54.3 \\
( \pm 9.2)\end{array}$ & $\begin{array}{c}70.8 \\
( \pm 10.7)\end{array}$ & $\begin{array}{c}61.6 \\
( \pm 14.7)\end{array}$ & $\begin{array}{c}71.8 \\
( \pm 13.7)\end{array}$ & $\begin{array}{c}66.9 \\
( \pm 15.8)\end{array}$ & $\begin{array}{c}68.0 \\
( \pm 13.8)\end{array}$ & $\begin{array}{c}53.8 \\
( \pm 9.1)\end{array}$ & $\begin{array}{c}69.7 \\
( \pm 12.3)\end{array}$ & $\begin{array}{c}52.3 \\
( \pm 18.4)\end{array}$ & $\begin{array}{c}71.3 \\
( \pm 13.5)\end{array}$ & $\begin{array}{c}66.4 \\
( \pm 13.9)\end{array}$ & $\begin{array}{c}61.1 \\
( \pm 17.4)\end{array}$ & - & - & - & - & - & - & - & - & - & - & - & - \\
\hline S.s. & $\begin{array}{r}29.1 \\
( \pm 5.9)\end{array}$ & $\begin{array}{c}36.7 \\
( \pm 9.1)\end{array}$ & $\begin{array}{l}21.3 \\
( \pm 7.1)\end{array}$ & $\begin{array}{c}36.6 \\
( \pm 8.0)\end{array}$ & $\begin{array}{c}36.7 \\
( \pm 8.8)\end{array}$ & $\begin{array}{c}25.6 \\
( \pm 14.2)\end{array}$ & $\begin{array}{c}29.1 \\
( \pm 6.5)\end{array}$ & $\begin{array}{c}35.8 \\
( \pm 7.9)\end{array}$ & $\begin{array}{c}21.3 \\
( \pm 7.1)\end{array}$ & $\begin{array}{c}35.5 \\
( \pm 9.2)\end{array}$ & $\begin{array}{c}35.8 \\
( \pm 9.2)\end{array}$ & $\begin{array}{c}25.6 \\
( \pm 11.7)\end{array}$ & - & - & - & - & - & - & - & - & - & - & - & - \\
\hline T.m. & $\begin{array}{l}64.7 \\
( \pm 6.4)\end{array}$ & $\begin{array}{l}69.9 \\
( \pm 6.0)\end{array}$ & $\begin{array}{c}80.7 \\
( \pm 9.4)\end{array}$ & $\begin{array}{l}76.3 \\
( \pm 7.5)\end{array}$ & $\begin{array}{c}75.8 \\
( \pm 6.8)\end{array}$ & $\begin{array}{l}78.8 \\
( \pm 7.2)\end{array}$ & $\begin{array}{l}64.9 \\
( \pm 6.5)\end{array}$ & $\begin{array}{c}70.4 \\
( \pm 5.6)\end{array}$ & $\begin{array}{c}78.2 \\
( \pm 9.9)\end{array}$ & $\begin{array}{l}76.0 \\
( \pm 6.8)\end{array}$ & $\begin{array}{l}75.6 \\
( \pm 7.2)\end{array}$ & $\begin{array}{c}78.9 \\
( \pm 9.7)\end{array}$ & - & - & - & - & - & - & - & - & - & - & - & - \\
\hline T.c. & $\begin{array}{c}58.3 \\
( \pm 11.5)\end{array}$ & $\begin{array}{l}65.4 \\
( \pm 12.5)\end{array}$ & $\begin{array}{c}72.2 \\
( \pm 14.8)\end{array}$ & $\begin{array}{c}65.8 \\
( \pm 14.4)\end{array}$ & $\begin{array}{c}52.1 \\
( \pm 13.6)\end{array}$ & $\begin{array}{c}72.5 \\
( \pm 15.1)\end{array}$ & $\begin{array}{c}58.2 \\
( \pm 10.9)\end{array}$ & $\begin{array}{c}65.4 \\
( \pm 12.7)\end{array}$ & $\begin{array}{c}69.6 \\
( \pm 13.4)\end{array}$ & $\begin{array}{r}63 \\
( \pm 1\end{array}$ & & $\begin{array}{c}70.6 \\
( \pm 14.2)\end{array}$ & - & - & - & - & - & - & - & - & - & - & - & - \\
\hline V.a. & $\begin{array}{l}68.2 \\
( \pm 8.7)\end{array}$ & $\begin{array}{c}72.8 \\
( \pm 12.2)\end{array}$ & $\begin{array}{c}65.1 \\
( \pm 12.8)\end{array}$ & $\begin{array}{c}74.4 \\
( \pm 12.0)\end{array}$ & $\begin{array}{c}74.4 \\
( \pm 12.2)\end{array}$ & $\begin{array}{c}66.9 \\
( \pm 13.3)\end{array}$ & $\begin{array}{l}66.5 \\
( \pm 10.4)\end{array}$ & $\begin{array}{c}74.1 \\
( \pm 12.0)\end{array}$ & $\begin{array}{c}63.9 \\
( \pm 13.3)\end{array}$ & $\begin{array}{c}74.4 \\
( \pm 12.1)\end{array}$ & $\begin{array}{c}73.6 \\
( \pm 11.1)\end{array}$ & $\begin{array}{l}64.6 \\
( \pm 12.5)\end{array}$ & - & - & - & - & - & - & - & - & - & - & - & - \\
\hline Average & 56.8 & 65.0 & 63.6 & 66.7 & 64.0 & 65.9 & 56.9 & 65.1 & 62.0 & 66.6 & 63.9 & 64.8 & 66.7 & 75.1 & 76.9 & 75.9 & 74.1 & 77.3 & 68.0 & 74.7 & 67.3 & 75.4 & 73.4 & 73.3 \\
\hline
\end{tabular}




\section{Appendix C. Experiment 3 (High Level of Impurity-Smaller Focal Training Class)_Complement}

The procedure was similar to Experiment 3 . We set aside 30\% of the data for validation. However, we selected only 30 crowns of the focal class to use in the training set. In addition, we selected 100,000 pixels from the non-focal species to make up the non-focal class. We simulated three level of bias in the training set as described below.

Table A3. Comparison of classification methods with and without bias. Plain and optimized indicate whether an optimization step (selecting a threshold probability value) was applied or not. This step aims at maximizing either the $\mathrm{F}$ measure $(0 \%$ contamination) or the Lee and Liu 2003 criterion ( $1 \%$ contamination). F-measure is given at object level. The best predictions for each species, configuration and method are in bold.

\begin{tabular}{|c|c|c|c|c|c|c|c|}
\hline \multirow{2}{*}{ SPID } & \multirow{2}{*}{ Bias } & \multicolumn{2}{|c|}{ LDA } & \multicolumn{2}{|c|}{ RDA } & \multicolumn{2}{|c|}{ LR } \\
\hline & & Plain & Optimized & Plain & Optimized & Plain & Optimized \\
\hline D.g. & 0 & $58.9( \pm 8.0)$ & $69.7( \pm 6.4)$ & $67.1( \pm 6.5)$ & $66.7( \pm 6.7)$ & $71.6( \pm 7.4)$ & $74.6( \pm 6.5)$ \\
\hline$\overline{\text { E.f. }}$ & 0 & $53.4( \pm 7.2)$ & $68.3( \pm 6.9)$ & $66.0( \pm 4.9)$ & $64.7( \pm 7.1)$ & $61.2( \pm 9.1)$ & $63.6( \pm 7.6)$ \\
\hline$\overline{E . S .}$ & 0 & $68.6( \pm 5.7)$ & $71.7( \pm 6.4)$ & $73.0( \pm 5.6)$ & $71.5( \pm 6.3)$ & $61.2( \pm 9.0)$ & $68.4( \pm 8.4)$ \\
\hline$\overline{\text { P.c. }}$ & 0 & $73.6( \pm 4.4)$ & $79.9( \pm 5.6)$ & $79.5( \pm 5.7)$ & $79.2( \pm 5.1)$ & $83.6( \pm 4.2)$ & $84.9( \pm 5.1)$ \\
\hline Q.r. & 0 & $88.8( \pm 2.7)$ & $89.5( \pm 2.6)$ & $89.4( \pm 2.6)$ & $89.4( \pm 2.7)$ & $90.2( \pm 2.9)$ & $90.9( \pm 3.0)$ \\
\hline Average & & 68.7 & 75.8 & 75.0 & 74.3 & 73.5 & 76.5 \\
\hline D.g. & $1 \%$ & $58.8( \pm 8.3)$ & $71.0( \pm 7.9)$ & $67.8( \pm 7.7)$ & $67.1( \pm 8.5)$ & $70.5( \pm 8.7)$ & $75.3( \pm 7.0)$ \\
\hline$\overline{\text { E.f. }}$ & $1 \%$ & $54.1( \pm 6.6)$ & $66.8( \pm 7.8)$ & $65.2( \pm 5.7)$ & $65.1( \pm 5.8)$ & $59.0( \pm 10.0)$ & $63.6( \pm 6.7)$ \\
\hline$\overline{E . S .}$ & $1 \%$ & $69.0( \pm 6.6)$ & $73.2( \pm 5.1)$ & $73.4( \pm 5.3)$ & $72.5( \pm 5.5)$ & $52.9( \pm 8.1)$ & $62.9( \pm 7.0)$ \\
\hline$\overline{\text { P.c. }}$ & $1 \%$ & $71.9( \pm 5.7)$ & $76.5( \pm 5.8)$ & $75.8( \pm 6.7)$ & $76.7( \pm 5.9)$ & $77.1( \pm 5.0)$ & $79.5( \pm 4.7)$ \\
\hline Q.r. & $1 \%$ & $89.2( \pm 2.9)$ & $89.2( \pm 2.3)$ & $89.2( \pm 2.9)$ & $88.9( \pm 2.7)$ & $87.2( \pm 3.6)$ & $88.5( \pm 3.6)$ \\
\hline Average & & 68.6 & 75.3 & 74.3 & 74.0 & 69.4 & 74.0 \\
\hline D.g. & $2 \%$ & $57.0( \pm 8.2)$ & $71.5( \pm 5.8)$ & $68.3( \pm 6.2)$ & $67.4( \pm 6.7)$ & $68.5( \pm 9.5)$ & $72.9( \pm 7.0)$ \\
\hline$\overline{E . f .}$ & $2 \%$ & $53.7( \pm 6.1)$ & $66.4( \pm 7.7)$ & $64.4( \pm 6.7)$ & $64.6( \pm 7.3)$ & $54.7( \pm 10.5)$ & $62.2( \pm 9.6)$ \\
\hline$\overline{E . s .}$ & $2 \%$ & $68.2( \pm 6.1)$ & $73.3( \pm 5.1)$ & $73.6( \pm 5.3)$ & $71.9( \pm 6.7)$ & $48.6( \pm 11.3)$ & $62.0( \pm 10.0)$ \\
\hline$\overline{\text { P.c. }}$ & $2 \%$ & $74.1( \pm 5.2)$ & $79.6( \pm 4.0)$ & $78.5( \pm 4.2)$ & $78.6( \pm 5.0)$ & $78.6( \pm 3.5)$ & $82.3( \pm 3.4)$ \\
\hline Q.r. & $2 \%$ & $88.7( \pm 2.9)$ & $89.3( \pm 2.9)$ & $89.3( \pm 2.7)$ & $89.3( \pm 2.9)$ & $84.2( \pm 3.0)$ & $87.5( \pm 2.7)$ \\
\hline Average & & 68.3 & 76.0 & 74.8 & 74.3 & 66.9 & 73.4 \\
\hline D.g. & $5 \%$ & $58.8( \pm 6.8)$ & $71.6( \pm 5.2)$ & $68.2( \pm 6.2)$ & $68.1( \pm 6.3)$ & $61.3( \pm 5.8)$ & $70.9( \pm 5.4)$ \\
\hline E.f. & $5 \%$ & $52.2( \pm 5.9)$ & $67.5( \pm 6.2)$ & $66.1( \pm 6.4)$ & $66.2( \pm 5.9)$ & $45.8( \pm 13.2)$ & $59.0( \pm 8.6)$ \\
\hline$\overline{E . s .}$ & $5 \%$ & $69.2( \pm 5.9)$ & $73.2( \pm 5.5)$ & $73.7( \pm 4.8)$ & $72.0( \pm 5.8)$ & $41.6( \pm 11.2)$ & $58.7( \pm 10.0)$ \\
\hline$\overline{\text { P.c. }}$ & $5 \%$ & $74.0( \pm 5.7)$ & $80.5( \pm 5.3)$ & $80.2( \pm 6.1)$ & $79.9( \pm 5.8)$ & $71.4( \pm 5.7)$ & $78.4( \pm 4.9)$ \\
\hline Q.r. & $5 \%$ & $88.6( \pm 2.9)$ & $89.4( \pm 2.9)$ & $89.9( \pm 2.6)$ & $89.2( \pm 3.1)$ & $74.5( \pm 5.5)$ & $83.4( \pm 6.0)$ \\
\hline Average & & 68.6 & 76.4 & 75.6 & 75.1 & 58.9 & 70.1 \\
\hline
\end{tabular}

The use of 30 crowns compared to the use of $70 \%$ of focal class crowns had no negative effect on the LDA and RDA method. Nevertheless, the LR method seemed to be more sensitive to the use of a smaller sample (from $79.1 \%$ to $73.5 \%$ or from $80.0 \%$ to $76.5 \%$ with optimisation step). The optimization step made up for part of the loss in performance of the F-measure. 


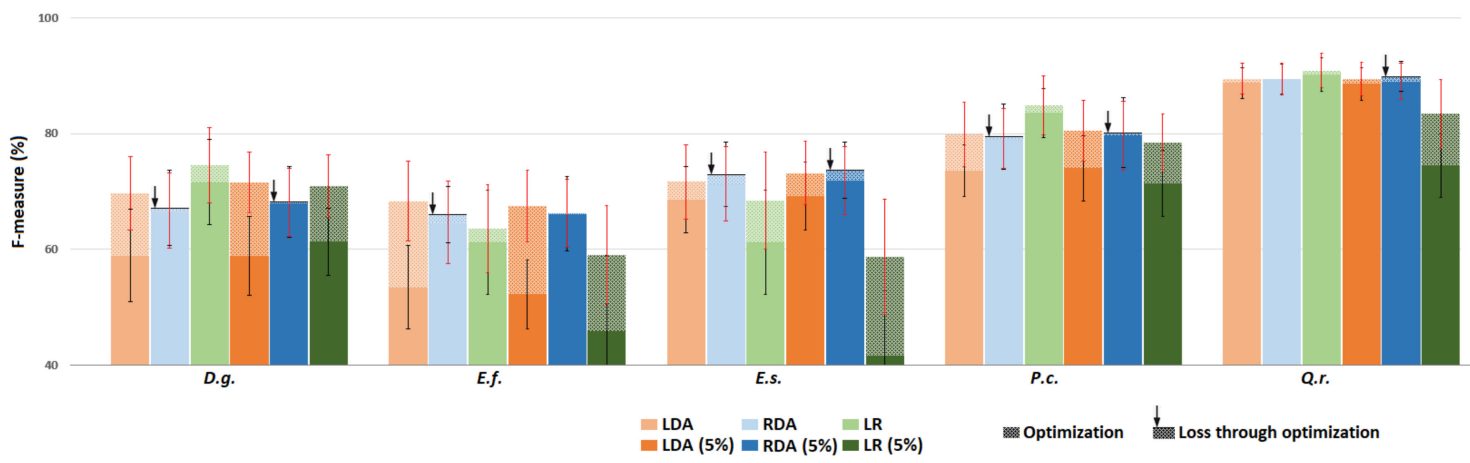

Figure A1. Comparison of classification methods with and without bias. F-measure and its standard deviation are given at object level. Only 30 crowns from the focus class and 100,000 pixels from the non-focus class were used to train the model. Bias consisted in adding $5 \%$ of the pixels of the focal species into the non-focal class. Optimization step is represented in the same paler colour. An arrow indicates when optimization decreased performance.

\section{Appendix D. Experiment 3 (Focal Class Purification)—Complement}

Removal of potential outliers' impact on F-measure of various classifiers.
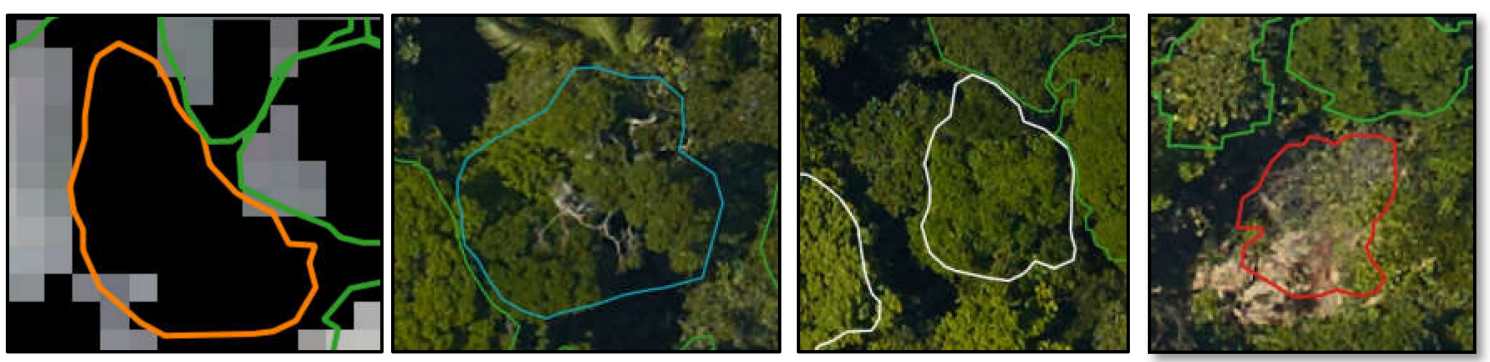

Figure A2. From left to right: low illumination ratio from hyperspectral images, wood contribution, lianas contribution and ground contribution.

Illustration of tree crowns considered as outliers is proposed above. Low illumination led to a reduction in the number of pixels inside the crowns (given by hyperspectral imagery). Other possible causes of outlier crowns are illustrated by RGB imagery. 
Table A4. Comparison between using all crowns and without some removed crowns based on the Mahalanobis distance. The F-measure is given at object level. Significance codes: ${ }^{*} p<0.1, * * p<0.05, * * * p 0.01$. The best predictions for each species, configuration and method are in bold.

\begin{tabular}{|c|c|c|c|c|c|c|c|c|c|}
\hline \multirow{2}{*}{$\begin{array}{c}\text { Removing } \\
\text { SPID }\end{array}$} & \multicolumn{3}{|c|}{ Without } & \multicolumn{3}{|c|}{ With } & \multirow{2}{*}{ Total Crowns } & \multirow{2}{*}{$\begin{array}{c}\text { Potential } \\
\text { Outliers }\end{array}$} & \multirow{2}{*}{$\begin{array}{c}\text { Proportion } \\
(\%)\end{array}$} \\
\hline & LDA & RDA & LR & LDA & RDA & LR & & & \\
\hline B.p. & $35.8( \pm 10.3)$ & $57.7( \pm 12.4)$ & $37.5( \pm 15.5)$ & $40.4( \pm 10.2)$ & $60.3( \pm 14.0)$ & $35.0( \pm 13.3)$ & 24 & 0 & 0.0 \\
\hline C.m. & $68.3( \pm 10.8)$ & $64.7( \pm 10.1)$ & $68.0( \pm 10.5)$ & $68.4( \pm 11.6)^{* *}$ & $65.5( \pm 9.8) * *$ & $71.8( \pm 9.1)^{* * *}$ & 49 & 1 & 2.0 \\
\hline D.g. & $57.7( \pm 3.9)$ & $72.3( \pm 6.0)$ & $78.2( \pm 6.1)$ & $55.9( \pm 5.2)$ & $69.6( \pm 5.9)$ & $76.6( \pm 5.7)$ & 108 & 5 & 4.6 \\
\hline$\frac{o}{E . f .}$ & $50.8( \pm 4.1)$ & $67.7( \pm 6.1)$ & $69.2( \pm 6.2)$ & $50.3( \pm 6.1)$ & $66.4( \pm 6.1)$ & $69.3( \pm 5.9)^{*}$ & 106 & 2 & 1.9 \\
\hline$\overline{\text { E.g. }}$ & $65.1( \pm 7.0)$ & $82.0( \pm 5.3)$ & $84.4( \pm 4.6)$ & $64.2( \pm 5.9)$ & $81.9( \pm 5.2)$ & $84.6( \pm 5.4)$ & 74 & 5 & 6.8 \\
\hline$\overline{\text { E.S. }}$ & $68.1( \pm 4.2)$ & $74.2( \pm 4.1)$ & $71.0( \pm 5.2)$ & $66.7( \pm 4.7)$ & $74.6( \pm 3.9)$ & $73.9( \pm 4.8)^{*}$ & 139 & 7 & 5.0 \\
\hline$\overline{G . g .}$ & $62.5( \pm 12.6)$ & $73.4( \pm 11.5)$ & $76.4( \pm 12.5)$ & $58.4( \pm 8.3)$ & $68.3( \pm 11.6)$ & $73.7( \pm 14.8)$ & 25 & 2 & 8.0 \\
\hline I.a. & $38.3( \pm 11.5)$ & $42.3( \pm 12.7)$ & $38.5( \pm 11.6)$ & $38.4( \pm 9.9)$ & $43.0( \pm 8.1)$ & $33.4( \pm 13.2)$ & 26 & 2 & 7.7 \\
\hline J.c. & $50.7( \pm 19.7)$ & $51.4( \pm 16.8)$ & $52.4( \pm 17.1)$ & $59.2( \pm 10.6)^{* *}$ & $58.5( \pm 10.2)$ & $57.4( \pm 12.6)$ & 24 & 2 & 8.3 \\
\hline L.a. & $41.6( \pm 8.7)$ & $56.3( \pm 10.8)$ & $53.9( \pm 10.5)$ & $43.3( \pm 7.0)$ & $53.3( \pm 8.3)$ & $50.1( \pm 13.7)$ & 46 & 0 & 0.0 \\
\hline L.h. & $25.6( \pm 8.9)$ & $43.6( \pm 11.0)$ & $22.8( \pm 8.1)$ & $27.9( \pm 10.9)$ & $44.0( \pm 16.7)$ & $26.9( \pm 8.6)$ & 27 & 1 & 3.7 \\
\hline M.c. & $58.5( \pm 13.8)$ & $55.5( \pm 16.9)$ & $60.0( \pm 14.5)$ & $60.1( \pm 11.1)$ & $59.9( \pm 14.9)$ & $66.7( \pm 12.1)$ & 27 & 2 & 7.4 \\
\hline P.c. & $69.5( \pm 4.5)$ & $77.1( \pm 4.9)$ & $85.9( \pm 3.6)$ & $69.2( \pm 4.2)$ & $79.0( \pm 3.7)$ & $85.7( \pm 3.7)$ & 164 & 6 & 3.7 \\
\hline Q.r. & $86.6( \pm 2.5)$ & $88.1( \pm 2.7)$ & $91.3( \pm 2.3)$ & $88.5( \pm 3.0)$ & $89.9( \pm 2.4)$ & $91.9( \pm 2.2)$ & 206 & 7 & 3.4 \\
\hline$\widetilde{\overline{R . s .}}$ & $82.5( \pm 3.8)$ & $78.8( \pm 4.5)$ & $81.2( \pm 5.2)$ & $83.1( \pm 7.6)$ & $80.5( \pm 7.7)$ & $83.8( \pm 6.3)^{* *}$ & 69 & 2 & 2.9 \\
\hline S.r. & $54.3( \pm 9.2)$ & $70.8( \pm 10.7)$ & $61.6( \pm 14.7)$ & $55.6( \pm 8.3)^{* * *}$ & $71.3( \pm 7.6)$ & $64.7( \pm 12.9) * * *$ & 32 & 2 & 6.3 \\
\hline S.s. & $29.1( \pm 5.9)$ & $36.7( \pm 9.1)$ & $21.3( \pm 7.1)$ & $29.8( \pm 7.6)$ & $36.1( \pm 11.5)$ & $22.4( \pm 6.9)$ & 34 & 2 & 5.9 \\
\hline T.m. & $64.7( \pm 6.4)$ & $69.9( \pm 6.0)$ & $80.7( \pm 9.4)$ & $64.6( \pm 11.5)$ & $69.6( \pm 11.8)$ & $82.0( \pm 6.4)$ & 51 & 4 & 7.8 \\
\hline T.c. & $58.3( \pm 11.5)$ & $65.4( \pm 12.5)$ & $72.2( \pm 14.8)$ & $55.8( \pm 9.0)$ & $68.0( \pm 12.8)$ * & $73.3( \pm 13.9)$ & 32 & 2 & 6.3 \\
\hline V.a. & $68.2( \pm 8.7)$ & $72.8( \pm 12.2)$ & $65.1( \pm 12.8)$ & $70.0( \pm 8.6)$ & $78.4( \pm 7.0)$ & $67.8( \pm 10.7)$ & 34 & 1 & 2.9 \\
\hline Average & 56.8 & 65.0 & 63.6 & 57.5 & 65.9 & 64.5 & 1297.0 & 55 & 4.2 \\
\hline
\end{tabular}




\section{Appendix E. Experiment 4-Complement}

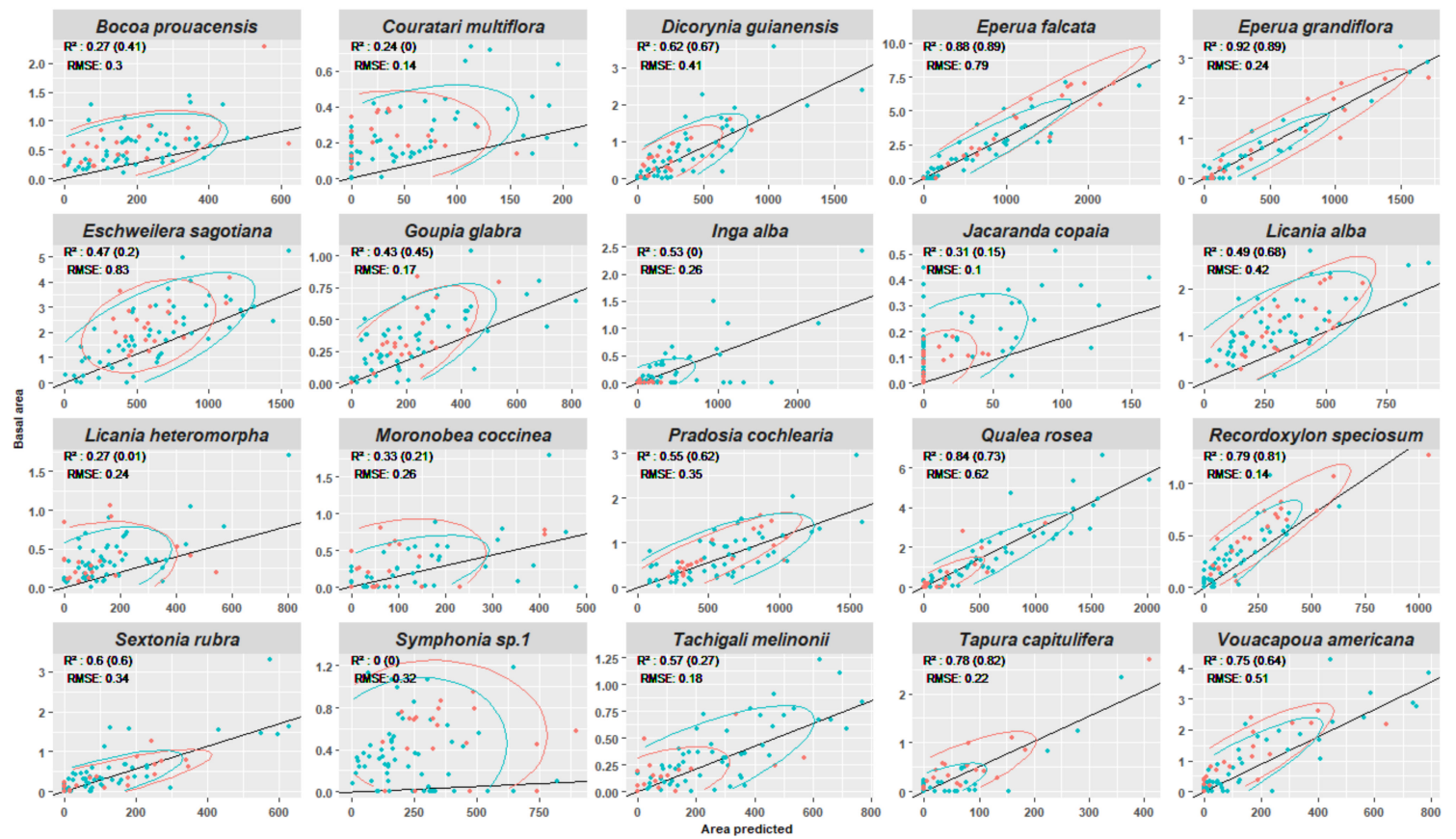

Figure A3. Relation between basal areal $\left(\mathrm{m}^{2} \cdot \mathrm{ha}^{-1}\right)$ and area predicted $\left(\mathrm{m}^{2} \cdot \mathrm{ha}^{-1}\right)$ using the optimized LDA. Plots not used for training are plotted in red and the R-squared for those observations are given in brackets. The plots used for the training are in blue. Global R-squares are given using all data points (red and blue). In solid black line, linear regression based on all points passing through zero. The normal confidence ellipses are given, computed for each group of points using the corresponding color (red or blue).

Figure A3 (basal area vs. prediction) is a fine representation of the behaviour of the classifier and makes it possible to understand the constraints. For example, one might think that the predictive performance of Inga alba is poor. However, on the plots never used for training (red point) we see that this species is not present. The classifier predicts few pixels of this species. The Jacaranda copaia is a species that has a low basal area; therefore, a prediction error is potentially more impacting than for the Eperua grandiflora. Note that the relationship between the basal area and the predicted area is different depending on the species considered, even for the species that have a high $\mathrm{R}^{2}$.

\section{Appendix F. Test of Correlation}

Data used to test the relationship between species object level F measure (obtained using and optimized LDA) and different metrics are given in Table A5. AB CA r2 is the linear regression coefficient between the predicted canopy coverage area for a particular species and its recorded basal area. Number of pixels is given per species. Intra-group variance was computed as proposed by [60]. Species mean Mahalanobis distance was computed as described in Section 2.6.3. Pseudo-outlier refers to number of outliers detected if Mahalanobis distance value is higher or lower than two standard deviations. 
Table A5. F-measure and various metrics tested for correlation.

\begin{tabular}{|c|c|c|c|c|c|c|c|}
\hline Species & $\begin{array}{c}\text { F-Measure } \\
\text { (Object Level) }\end{array}$ & $\mathrm{BA} \sim \mathrm{CA} \mathrm{r}^{2}$ & $\begin{array}{l}\text { Number } \\
\text { of Pixels }\end{array}$ & $\begin{array}{l}\text { Number } \\
\text { of Crowns }\end{array}$ & $\begin{array}{c}\text { Intra } \\
\text { Group } \\
\text { Variance }\end{array}$ & $\begin{array}{c}\text { Mean Species } \\
\text { Mahalanobis } \\
\text { Distance }\end{array}$ & $\begin{array}{c}\text { Pseudo } \\
\text { Outlier } \\
(\%)\end{array}$ \\
\hline B.p. & 65.4 & 0.27 & 2375 & 24 & 60716044 & 398 & 0 \\
\hline C.m. & 69.8 & 0.24 & 4850 & 49 & 42710171 & 382 & 2 \\
\hline D.g. & 75.8 & 0.62 & 18,589 & 108 & 88937469 & 383 & 4.6 \\
\hline$\overline{E . f .}$ & 71.5 & 0.84 & 15,355 & 106 & 41768295 & 383 & 1.9 \\
\hline$\overline{E . g}$. & 82.4 & 0.92 & 10,859 & 74 & 37064303 & 378 & 6.8 \\
\hline$\overline{E . s .}$ & 74.7 & 0.47 & 12,559 & 139 & 42879098 & 382 & 5 \\
\hline$\overline{\text { G.g. }}$ & 74.5 & 0.43 & 4998 & 25 & 45436876 & 387 & 8 \\
\hline I.a. & 43.0 & 0.53 & 3846 & 26 & 73845080 & 394 & 7.7 \\
\hline J.c. & 50.9 & 0.31 & 1705 & 24 & 50504397 & 417 & 8.3 \\
\hline L.a. & 56.6 & 0.49 & 3894 & 46 & 49323222 & 386 & 0 \\
\hline L.h. & 44.0 & 0.27 & 1437 & 27 & 35529833 & 412 & 3.7 \\
\hline M.c. & 56.3 & 0.33 & 3355 & 27 & 53471810 & 381 & 7.4 \\
\hline P.c. & 77.6 & 0.55 & 38,349 & 164 & 46398429 & 374 & 3.7 \\
\hline Q.r. & 86.4 & 0.84 & 27,828 & 206 & 51460549 & 374 & 3.4 \\
\hline$\overline{R . s .}$ & 81.0 & 0.79 & 7944 & 69 & 120765823 & 382 & 2.9 \\
\hline S.r. & 71.8 & 0.60 & 4070 & 32 & 31609536 & 417 & 6.3 \\
\hline S.s. & 36.6 & 0.00 & 3355 & 34 & 38010280 & 378 & 5.9 \\
\hline T.m. & 76.3 & 0.57 & 6745 & 51 & 80924196 & 392 & 7.8 \\
\hline T.c. & 65.8 & 0.78 & 1224 & 32 & 36278962 & 388 & 6.3 \\
\hline$\underline{\text { V.a. }}$ & 74.4 & 0.75 & 3218 & 34 & 137806130 & 387 & 2.9 \\
\hline $\begin{array}{l}\text { Pearson } \\
\text { Cor. Coeff }\end{array}$ & - & $0.71 * *$ & 0.54 * & $0.59^{* * *}$ & 0.28 & 0.08 & 0.48 \\
\hline $\begin{array}{l}\text { Spearman } \\
\text { Cor. Coeff. }\end{array}$ & - & $0.69 * *$ & $0.77 * *$ & $0.71^{* * *}$ & 0.22 & -0.44 & -0.09 \\
\hline
\end{tabular}

\section{References}

1. Corlett, R.T. Plant diversity in a changing world: Status, trends, and conservation needs. Plant Divers. 2016, 38, 10-16. [CrossRef]

2. Peres, C.A.; Gardner, T.A.; Barlow, J.; Zuanon, J.; Michalski, F.; Lees, A.C.; Vieira, I.C.G.; Moreira, F.M.S.; Feeley, K.J. Biodiversity conservation in human-modified Amazonian forest landscapes. Biol. Conserv. 2010, 143, 2314-2327. [CrossRef]

3. Leisher, C.; Touval, J.; Hess, S.M.; Boucher, T.M.; Reymondin, L. Land and Forest Degradation inside Protected Areas in Latin America. Diversity 2013, 5, 779-795. [CrossRef]

4. Sala, O.E. Global Biodiversity Scenarios for the Year 2100. Science 2000, 287, 1770-1774. [CrossRef] [PubMed]

5. Burivalova, Z.; Şekercioğlu, Ç.H.; Koh, L.P. Thresholds of Logging Intensity to Maintain Tropical Forest Biodiversity. Curr. Biol. 2014, 24, 1893-1898. [CrossRef] [PubMed]

6. Putz, F.E.; Zuidema, P.A.; Pinard, M.A.; Boot, R.G.A.; Sayer, J.A.; Sheil, D.; Sist, P.; Vanclay, J.K. Improved Tropical Forest Management for Carbon Retention. PLoS Biol. 2008, 6, e166. [CrossRef]

7. Sist, P.; Mazzei, L.; Blanc, L.; Rutishauser, E. Large trees as key elements of carbon storage and dynamics after selective logging in the Eastern Amazon. For. Ecol. Manag. 2014, 318, 103-109. [CrossRef]

8. Putz, F.E. Woody vines and forest management in Malaysia. Commonw. For. Rev. 1985, 64, 359-365.

9. The Biology of Vines; Putz, F.E.; Mooney, H.A. (Eds.) Cambridge University Press: Cambridge, UK; New York, NY, USA, 1991; ISBN 978-0-521-39250-1.

10. Ouédraogo, D.-Y.; Beina, D.; Picard, N.; Mortier, F.; Baya, F.; Gourlet-Fleury, S. Thinning after selective logging facilitates floristic composition recovery in a tropical rain forest of Central Africa. For. Ecol. Manag. 2011, 262, 2176-2186. [CrossRef]

11. Alroy, J. Effects of habitat disturbance on tropical forest biodiversity. Proc. Natl. Acad. Sci. USA 2017, 114, 6056. [CrossRef]

12. Kennard, D.K.; Gould, K.; Putz, F.E.; Fredericksen, T.S.; Morales, F. Effect of disturbance intensity on regeneration mechanisms in a tropical dry forest. For. Ecol. Manag. 2002, 162, 197-208. [CrossRef]

13. Chaudhary, A.; Burivalova, Z.; Koh, L.P.; Hellweg, S. Impact of Forest Management on Species Richness: Global Meta-Analysis and Economic Trade-Offs. Sci. Rep. 2016, 6, 23954. [CrossRef] [PubMed] 
14. Huang, C.; Asner, G.P. Applications of Remote Sensing to Alien Invasive Plant Studies. Sensors 2009, 9, 4869-4889. [CrossRef] [PubMed]

15. Ustin, S.L.; DiPietro, D.; Olmstead, K.; Underwood, E.; Scheer, G.J. Hyperspectral remote sensing for invasive species detection and mapping. In Proceedings of the IEEE International Geoscience and Remote Sensing Symposium, Toronto, ON, Canada, 24-28 June 2002; Volume 3, pp. 1658-1660.

16. Waite, C.E.; van der Heijden, G.M.F.; Field, R.; Boyd, D.S. A view from above: Unmanned aerial vehicles (UAVs) provide a new tool for assessing liana infestation in tropical forest canopies. J. Appl. Ecol. 2019. [CrossRef]

17. Sist, P. Reduced-impact logging in the tropics: Objectives, principles and impacts. Int. For. Rev. 2000, 2, 3-10.

18. Baldeck, C.; Asner, G. Improving Remote Species Identification through Efficient Training Data Collection. Remote Sens. 2014, 6, 2682-2698. [CrossRef]

19. Baldeck, C.A.; Asner, G.P.; Martin, R.E.; Anderson, C.B.; Knapp, D.E.; Kellner, J.R.; Wright, S.J. Operational Tree Species Mapping in a Diverse Tropical Forest with Airborne Imaging Spectroscopy. PLoS ONE 2015, 10, e0118403. [CrossRef]

20. Feret, J.-B.; Asner, G.P. Tree Species Discrimination in Tropical Forests Using Airborne Imaging Spectroscopy. IEEE Trans. Geosci. Remote Sens. 2013, 51, 73-84. [CrossRef]

21. Harrison, D.; Rivard, B.; Sánchez-Azofeifa, A. Classification of tree species based on longwave hyperspectral data from leaves, a case study for a tropical dry forest. Int. J. Appl. Earth Obs. Geoinf. 2018, 66, 93-105. [CrossRef]

22. Laybros, A.; Schläpfer, D.; Féret, J.-B.; Descroix, L.; Bedeau, C.; Lefevre, M.-J.; Vincent, G. Across Date Species Detection Using Airborne Imaging Spectroscopy. Remote Sens. 2019, 11, 789. [CrossRef]

23. Clark, M.; Roberts, D.; Clark, D. Hyperspectral discrimination of tropical rain forest tree species at leaf to crown scales. Remote Sens. Environ. 2005, 96, 375-398. [CrossRef]

24. Ferreira, M.P.; Zortea, M.; Zanotta, D.C.; Feret, J.B.; Shimabukuro, Y.E.; Filho, C.R. On the use of shortwave infrared for tree species discrimination in tropical semideciduous forest. In Proceedings of the ISPRS Geospatial Week 2015, La Grande Motte, France, 28 September-3 October 2015; Volume XL-3/W3, pp. 473-476.

25. Clark, M.L.; Roberts, D.A. Species-Level Differences in Hyperspectral Metrics among Tropical Rainforest Trees as Determined by a Tree-Based Classifier. Remote Sens. 2012, 4, 1820-1855. [CrossRef]

26. Dalponte, M.; Orka, H.O.; Gobakken, T.; Gianelle, D.; Naesset, E. Tree Species Classification in Boreal Forests with Hyperspectral Data. IEEE Trans. Geosci. Remote Sens. 2013, 51, 2632-2645. [CrossRef]

27. Aubry-Kientz, M.; Dutrieux, R.; Ferraz, A.; Saatchi, S.; Hamraz, H.; Williams, J.; Coomes, D.; Piboule, A.; Vincent, G. A Comparative Assessment of the Performance of Individual Tree Crowns Delineation Algorithms from ALS Data in Tropical Forests. Remote Sens. 2019, 11, 1086. [CrossRef]

28. Tochon, G.; Féret, J.B.; Valero, S.; Martin, R.E.; Knapp, D.E.; Salembier, P.; Chanussot, J.; Asner, G.P. On the use of binary partition trees for the tree crown segmentation of tropical rainforest hyperspectral images. Remote Sens. Environ. 2015, 159, 318-331. [CrossRef]

29. Lee, W.S.; Liu, B. Learning with Positive and Unlabeled Examples Using Weighted Logistic Regression. ICML 2003, 3, 448-455.

30. Ecology and Management of a Neotropical Rainforest: Lessons Drawn from Paracou, a Long-Term Experimental Research Site in French Guiana; Gourlet-Fleury, S.; Guehl, J.-M.; Laroussinie, O.; ECOFOR (Group). Elsevier: Paris, France, 2004; ISBN 978-2-84299-455-6.

31. Richter, R.; Schlapfer, D. Atmospheric/Topographic Correction for Airborne Imagery (ATCOR-4 User Guide, Version 7.2.0); ReSe Applications LLC: Wil, Switzerland, 2018; p. 279.

32. Schlapfer, D. PARametric Geocoding, Orthorectification for Airborne Scanner Data, User Manual Version 2.3; ReSe Applications Schlaepfer and Remote Sensing Laboratories (RSL) of the University of Zurich: Zurich, Switzerland, 2006.

33. Galvão, L.S.; Ponzoni, F.J.; Epiphanio, J.C.N.; Rudorff, B.F.T.; Formaggio, A.R. Sun and view angle effects on NDVI determination of land cover types in the Brazilian Amazon region with hyperspectral data. Int. J. Remote Sens. 2004, 25, 1861-1879. [CrossRef]

34. Ferraz, A.; Saatchi, S.; Mallet, C.; Meyer, V. Lidar detection of individual tree size in tropical forests. Remote Sens. Environ. 2016, 183, 318-333. [CrossRef]

35. Xiao, W.; Zaforemska, A.; Smigaj, M.; Wang, Y.; Gaulton, R. Mean Shift Segmentation Assessment for Individual Forest Tree Delineation from Airborne Lidar Data. Remote Sens. 2019, 11, 1263. [CrossRef] 
36. Roussel, J.-R.; Auty, D.; De Boissieu, F.; Meador, A. lidR: Airborne LiDAR Data Manipulation and Visualization for Forestry Applications; R Core Team: Vienna, Austria, 2018.

37. Pedregosa, F.; Varoquaux, G.; Gramfort, A.; Michel, V.; Thirion, B.; Grisel, O.; Blondel, M.; Prettenhofer, P.; Weiss, R.; Dubourg, V.; et al. Scikit-learn: Machine Learning in Python. Mach. Learn. PYTHON 2011, 12, 2825-2830.

38. Kurtzer, G.M.; Sochat, V.; Bauer, M.W. Singularity: Scientific containers for mobility of compute. PLoS ONE 2017, 12, e0177459. [CrossRef]

39. Yu, H.; Yang, J. A direct LDA algorithm for high-dimensional data-With application to face recognition. Pattern Recognit. 2001, 34, 2067-2070. [CrossRef]

40. Duda, R.O.; Hart, P.E.; Stork, D.G. Pattern Classification; John Wiley \& Sons: Hoboken, NJ, USA, 2012; ISBN 978-1-118-58600-6.

41. Friedman, J.H. Regularized Discriminant Analysis. J. Am. Stat. Assoc. 1989, 84, 165-175. [CrossRef]

42. Guo, Y.; Hastie, T.; Tibshirani, R. Regularized Discriminant Analysis and Its Application in Microarrays; Dept. of Statistics, Stanford University: Stanford, CA, USA, 2005; p. 18.

43. Pohar, M.; Blas, M.; Turk, S. Comparison of Logistic Regression and Linear Discriminant Analysis: A Simulation Study. Metodol. Zv. 2004, 1, 143.

44. Ferreira, M.P.; Zortea, M.; Zanotta, D.C.; Shimabukuro, Y.E.; de Souza Filho, C.R. Mapping tree species in tropical seasonal semi-deciduous forests with hyperspectral and multispectral data. Remote Sens. Environ. 2016, 179, 66-78. [CrossRef]

45. Graves, S.J.; Asner, G.P.; Martin, R.E.; Anderson, C.B.; Colgan, M.S.; Kalantari, L.; Bohlman, S.A. Tree Species Abundance Predictions in a Tropical Agricultural Landscape with a Supervised Classification Model and Imbalanced Data. Remote Sens. 2016, 8, 161. [CrossRef]

46. Naidoo, L.; Cho, M.A.; Mathieu, R.; Asner, G. Classification of savanna tree species, in the Greater Kruger National Park region, by integrating hyperspectral and LiDAR data in a Random Forest data mining environment. ISPRS J. Photogramm. Remote Sens. 2012, 69, 167-179. [CrossRef]

47. Akbani, R.; Kwek, S.; Japkowicz, N. Applying Support Vector Machines to Imbalanced Datasets. In Proceedings of the Machine Learning: ECML 2004, Pisa, Italy, 20-24 September 2004; Boulicaut, J.-F., Esposito, F., Giannotti, F., Pedreschi, D., Eds.; Springer: Berlin, Heidelberg, 2004; pp. 39-50.

48. Imam, T.; Ting, K.M.; Kamruzzaman, J. z-SVM: An SVM for Improved Classification of Imbalanced Data. In Proceedings of the AI 2006: Advances in Artificial Intelligence, Hobart, Australia, 4-8 December 2006; Sattar, A., Kang, B., Eds.; Springer: Berlin, Heidelberg, 2006; pp. 264-273.

49. Lin, W.-J.; Chen, J.J. Class-imbalanced classifiers for high-dimensional data. Brief. Bioinform. 2013, 14, 13-26. [CrossRef]

50. Wu, G.; Chang, E.Y. Adaptive Feature-Space Conformal Transformation for Imbalanced-Data Learning. In Proceedings of the 20th International Conference on Machine Learning (ICML-03), Washington, DC, USA, 21-24 August 2013; p. 8.

51. Baldeck, C.A.; Asner, G.P. Single-Species Detection with Airborne Imaging Spectroscopy Data: A Comparison of Support Vector Techniques. IEEE J. Sel. Top. Appl. Earth Obs. Remote Sens. 2015, 8, 2501-2512. [CrossRef]

52. Xue, J.-H.; Titterington, D.M. Do unbalanced data have a negative effect on LDA? Pattern Recognit. 2008, 41, 1558-1571. [CrossRef]

53. Ter Steege, H.; Pitman, N.C.A.; Sabatier, D.; Baraloto, C.; Salomao, R.P.; Guevara, J.E.; Phillips, O.L.; Castilho, C.V.; Magnusson, W.E.; Molino, J.-F.; et al. Hyperdominance in the Amazonian Tree Flora. Science 2013, 342, 1243092. [CrossRef]

54. Sabatier, D.; Grimaldi, M.; Prévost, M.-F.; Guillaume, J.; Godron, M.; Dosso, M.; Curmi, P. The influence of soil cover organization on the floristic and structural heterogeneity of a Guianan rain forest. Plant Ecol. 1997, 131, 81-108. [CrossRef]

55. Traissac, S. Dynamique Spatiale de Vouacapoua Americana, Arbre de Foret Tropicale Humide a Repartition Agregee; Université Claude Bernard Lyon 1: Villeurbanne, France, 2003.

56. Traissac, S.; Pascal, J.-P. Birth and life of tree aggregates in tropical forest: Hypotheses on population dynamics of an aggregated shade-tolerant species. J. Veg. Sci. 2014, 25, 491-502. [CrossRef]

57. Fonty, É; Molino, J.-F.; Prévost, M.-F.; Sabatier, D. A new case of neotropical monodominant forest: Spirotropis longifolia (Leguminosae-Papilionoideae) in French Guiana. J. Trop. Ecol. 2011, 27, 641-644. [CrossRef] 
58. Pitman, N.C.A.; Terborgh, J.; Silman, M.R.; Nuñez, V.P. Tree Species Distributions in an Upper Amazonian Forest. Ecology 1999, 80, 2651-2661. [CrossRef]

59. Marcon, E.; Scotti, I.; Hérault, B.; Rossi, V.; Lang, G. Generalization of the Partitioning of Shannon Diversity. PLOS ONE 2014, 9. [CrossRef]

60. Laliberté, E.; Schweiger, A.K.; Legendre, P. Partitioning plant spectral diversity into alpha and beta components. Ecol. Lett. 2020, 23, 370-380. [CrossRef]

61. Jucker, T.; Caspersen, J.; Chave, J.; Antin, C.; Barbier, N.; Bongers, F.; Dalponte, M.; van Ewijk, K.Y.; Forrester, D.I.; Haeni, M.; et al. Allometric equations for integrating remote sensing imagery into forest monitoring programmes. Glob. Chang. Biol. 2017, 23, 177-190. [CrossRef]

62. Antin, C.; Pélissier, R.; Vincent, G.; Couteron, P. Crown allometries are less responsive than stem allometry to tree size and habitat variations in an Indian monsoon forest. Trees 2013, 27, 1485-1495. [CrossRef]

63. Harja, D.; Vincent, G.; Mulia, R.; Noordwijk, M. Tree shape plasticity in relation to crown exposure. Trees 2012, 26, 1275-1285. [CrossRef]

64. Brell, M.; Rogass, C.; Segl, K.; Bookhagen, B.; Guanter, L. Improving Sensor Fusion: A Parametric Method for the Geometric Coalignment of Airborne Hyperspectral and Lidar Data. IEEE Trans. Geosci. Remote Sens. 2016, 54, 3460-3474. [CrossRef]

65. Tusa, E.; Laybros, A.; Monnet, J.-M.; Dalla Mura, M.; Barré, J.-B.; Vincent, G.; Dalponte, M.; Féret, J.-B.; Chanussot, J. Fusion of hyperspectral imaging and LiDAR for forest monitoring. In Data Handling in Science and Technology; Elsevier: Amsterdam, The Netherlands, 2020; Volume 32, pp. 281-303. ISBN 978-0-444-63977-6.

66. Reich, P.B. Phenology of tropical forests: Patterns, causes, and consequences. Can. J. Bot. 1995, 73, $164-174$. [CrossRef]

67. Laurans, M.; Martin, O.; Nicolini, E.; Vincent, G. Functional traits and their plasticity predict tropical trees regeneration niche even among species with intermediate light requirements. J. Ecol. 2012, 100, 1440-1452. [CrossRef]

68. Reich, P.B.; Uhl, C.; Walters, M.B.; Prugh, L.; Ellsworth, D.S. Leaf demography and phenology in Amazonian rain forest: A census of 40000 leaves of 23 tree species. Ecol. Monogr. 2004, 74, 3-23. [CrossRef]

69. Korpela, I.; Heikkinen, V.; Honkavaara, E.; Rohrbach, F.; Tokola, T. Variation and directional anisotropy of reflectance at the crown scale-Implications for tree species classification in digital aerial images. Remote Sens. Environ. 2011, 115, 2062-2074. [CrossRef]

70. Loubry, D. Déterminisme du Comportement Phénologique des Arbres en Forêt Tropicale Humide de Guyane Française (5 lat. n.); Université de Paris 6: Paris, France, 1994.

71. Saini, M.; Christian, B.; Joshi, N.; Vyas, D.; Marpu, P.; Krishnayya, N.S.R. Hyperspectral Data Dimensionality Reduction and the Impact of Multi-Seasonal Hyperion EO-1 Imagery on Classification Accuracies of Tropical Forest Species. Available online: https://www.ingentaconnect.com/content/asprs/pers/2014/00000080/ 00000008/art00005 (accessed on 2 May 2020).

72. Yadava, U.L. A Rapid and Non-destructive Method to Determine Chlorophyll in Intact Leaves. HortScience 1986, 21, 1449-1450.

73. Schlapfer, D.; Richter, R. Evaluation of brefcor BRDF effects correction for HYSPEX, CASI, and APEX imaging spectroscopy data. In Proceedings of the 2014 6th Workshop on Hyperspectral Image and Signal Processing: Evolution in Remote Sensing (WHISPERS), Lausanne, Switzerland, 24-27 June 2014; IEEE: Lausanne, Switzerland, 2014; pp. 1-4.

(C) 2020 by the authors. Licensee MDPI, Basel, Switzerland. This article is an open access article distributed under the terms and conditions of the Creative Commons Attribution (CC BY) license (http://creativecommons.org/licenses/by/4.0/). 